\title{
A Theory of Housing Demand Shocks
}

\author{
Zheng Liu, Pengfei Wang, and Tao Zha
}

\section{Working Paper 2019-4 \\ March 2019}

Abstract: Aggregate housing demand shocks are an important source of house price fluctuations in the standard macroeconomic models, and through the collateral channel, they drive macroeconomic fluctuations. These reduced-form shocks, however, fail to generate a highly volatile price-to-rent ratio that comoves with the house price observed in the data (the "price-rent puzzle"). We build a tractable heterogeneous-agent model that provides a microeconomic foundation for housing demand shocks. The model predicts that a credit supply shock can generate large comovements between the house price and the price-to-rent ratio. We provide empirical evidence from cross-country and cross-MSA data to support this theoretical prediction.

JEL classification: E21, E44, G21

Key words: price-rent puzzle, heterogeneity, marginal agent, cutoff point, liquidity premium, price-torent ratio, collateral constraint

https://doi.org/10.29338/wp2019-04

The research is supported in part by the National Science Foundation Grant SES 1558486 through the National Bureau of Economic Research and by the National Natural Science Foundation of China Project Numbers 71633003, 71742004, and 71473168. For helpful comments, the authors are grateful to Regis Barnichon, Adam Guren, Oscar Jorda, Greg Kaplan, Monika Piazzesi, Amir Sufi, and Gianluca Violante. They also thank seminar and conference participants at the Federal Reserve Bank of San Francisco, Academia Sinica (Taipei), the 2018 Academy of Financial Research Summer Institute of Economics and Finance at Zhejiang University, University of California Santa Cruz, University of Chicago, and the 2018 Hong Kong University of Science and Technology Workshop on Macroeconomics. Eric Tallman provided excellent research assistance. The views expressed here are those of the authors and not necessarily those of the Federal Reserve Banks of Atlanta and San Francisco or the Federal Reserve System or National Bureau of Economic Research. Any remaining errors are the authors' responsibility.

Please address questions regarding content to Zheng Liu, Research Department, Federal Reserve Bank of San Francisco, 101 Market Street, San Francisco, CA 94105, zliu001@gmail.com; Pengfei Wang, Department of Economics, Hong Kong University of Science and Technology, Hong Kong, pfwanghkust@gmail.com; or Tao Zha, Research Department, Federal Reserve Bank of Atlanta, Emory University, and NBER, 1000 Peachtree Street NE, Atlanta, GA 30309-4470, 404-498-8353, zmail@tzha.net.

Federal Reserve Bank of Atlanta working papers, including revised versions, are available on the Atlanta Fed's website at www.frbatlanta.org. Click "Publications" and then "Working Papers." To receive e-mail notifications about new papers, use frbatlanta.org/forms/subscribe. 


\section{INTRODUCTION}

The 2008 financial crisis was triggered by a collapse of the U.S. housing market. The empirical macroeconomic literature suggests that housing demand shocks be the primary driving force for the house price fluctuation (Davis and Heathcote, 2007). Working through the collateral channel, these shocks also drive a large fraction of business-cycle fluctuations (Iacoviello and Neri, 2010; Liu et al., 2013). In these standard macroeconomic models, aggregate housing demand shocks are proxied by shifts in the representative agent's preference for housing services. Such taste shifts are of reduced form without an explicit microeconomic justification. A housing demand shock drives the house price fluctuation through the fluctuation of the implicit rent, implying a counterfactually large volatility of rent.

In the data, however, the house price fluctuates much more than the rent, and the price-to-rent ratio is highly volatile and strongly comoves with the house price. These patterns are observed not only in the United States (Figure 1) but also in other OECD countries as well as in various U.S. Metropolitan Statistical Areas (MSAs) (Figure 2). Why does the price-to-rent ratio fluctuate so much, which we call the "price-rent puzzle?" This paper develops a tractable heterogeneous-agent model that provides a microeconomic foundation for aggregate housing demand shocks. Built on this foundation, we offer a theoretical explanation of the observed large fluctuation in the price-to-rent ratio.

Our baseline model features a large number of household members, each facing an idiosyncratic shock to their utility of housing services. In the decentralized housing market, agents finance house purchases with both internal funds and external debts. External financing is subject to a collateral constraint. For a given loan-to-value ratio, there exists a cutoff point in the support of the idiosyncratic shock distribution such that agents with the marginal utility of housing services above the cutoff point face binding collateral constraints, whereas those below the cutoff point are unconstrained. The cutoff point is endogenous. It depends on the distribution of idiosyncratic shocks and it varies with changes in the credit supply condition.

The house price in the model is determined by the the marginal rate of substitution (MRS) between housing services and non-housing consumption for the marginal agent, who has an idiosyncratic shock at the cutoff level. Since credit-constrained agents have a higher marginal utility than unconstrained agents, the marginal agent has the lowest MRS among all constrained agents or the highest MRS among all unconstrained agents. A credit supply expansion changes not only the identity of the marginal agent 
(the extensive margin) but also the quantity of house purchases by the new marginal agent (the intensive margin). In particular, an increase in credit supply makes some agents with high MRS who were initially credit-constrained become unconstrained. As a result, the new marginal agent has a higher MRS, and this extensive margin of adjustments tends to raise the house price. On the other hand, an increase in credit supply also reallocates more housing to the new marginal agent, reducing the agent's MRS because of the diminishing marginal utility. The relative strength of the two opposing effects depends on the risk aversion with respect to housing services. If the housing risk version is sufficiently large, the diminishing marginal utility effect dominates; thus, an increase in credit supply reduces the marginal agent's MRS and the house price falls. If the housing risk aversion is low, the opposite is true and an increase in credit supply raises the house price.

With a relatively low risk aversion with respect to housing services, an expansion in credit supply raises the house price but it does not have a direct impact on the rent. Heterogeneity in the marginal utility of housing services, together with credit constraints, is the key to understanding the difference between the dynamic responses of the house price and the rent. Aggregation results in a mapping between the reducedform housing demand shock in the representative-agent model and the sum of the implicit rent and the liquidity premium in the heterogeneous-agent model. This mapping provides a microeconomic foundation for aggregate housing demand shocks. As a result, the equilibrium house price depends on the present values of two components: (1) the rent that equals to the average MRS across all agents and (2) the liquidity premium that arises from binding collateral constraints for a subset of agents with a high marginal utility of housing services. The liquidity premium drives a wedge between the house price and the rent, creating room for the price-to-rent ratio to fluctuate in response to a credit supply shock.

Two important works, Favilukis et al. (2016) and Kaplan et al. (2017), study the driving forces of the house price as well as the price-to-rent ratio in two different models: one with overlapping generations and the other with incomplete markets. Favilukis et al. (2016) emphasize the importance of aggregate business-cycle risks and the wealth distribution driven by bequest heterogeneity in preferences in understanding the house price boom. Kaplan et al. (2017) argue that shifts in belief about future housing demand drives movements of the house price and the price-to-rent ratio around the Great Recession. Our heterogeneous-agent model places a different emphasis: we study how a credit supply shock affects the composition of credit-constrained 
and unconstrained agents and how changes in the composition affect the liquidity premium. The compositional effect is consistent with Landvoigt et al. (2015) who find that increased credit availability for poor households with low-end homes was a major driver of the house price boom in the early 2000s because households with smaller houses have a higher marginal utility of housing services. ${ }^{1}$

We provide empirical evidence, across countries and across U.S. MSAs, to corroborate our theoretical finding that a credit supply shock drives a large fluctuation in the house price but not the rent as well as a strong comovement between the house price and the price-to-rent ratio. ${ }^{2}$ For the cross-country data from 1965 to 2013, we use an unbalanced panel of 25 advanced economies. Following the approach of Mian et al. (2017), we construct credit supply shocks based on accelerations in household credit growth in periods when mortgage spreads were low, where the mortgage spread is the difference between the mortgage interest rate and 10-year sovereign bond yield. We find that an increase in credit supply is followed by a significant and persistent increase in the house price and the price-to-rent ratio, but it has no significant impact on the rent. For the MSA data from 1978 to 2017, we use an unbalanced panel of 21 MSAs within the U.S. and find that a credit supply shock generates the dynamic responses of the house price, the rent, and the price-rent ratio very similar to those obtained from the international data. These empirical findings lend credence to our model's mechanism.

The rest of the paper is organized as follows. We present a stylized representativeagent model in Section II to highlight the price-rent puzzle. We then present in Section III a baseline heterogenous-agent model with idiosyncratic shocks to individual preferences for housing services. In Section IV, we characterize the equilibrium of the heterogeneous-agent economy and show how changes in credit supply can drive aggregate housing demand and the price-to-rent ratio. To gain the key insight of the equilibrium, we provide an illustrative example, in Section $\mathrm{V}$, that enables us to derive the closed-form solution to the equilibrium. Section VI provides empirical evidence in support of the model's main prediction with panel regressions based on two distinct datasets. Section VII concludes.

\footnotetext{
${ }^{1}$ Agents with higher marginal utility in our model can be broadly interpreted as corresponding to households with smaller houses (low-end homes). This interpretation is formalized in an alternative setup in which household heterogeneity stems from idiosyncratic income shocks, as shown in Appendix A.

${ }^{2}$ For more empirical studies that stress the importance of credit supply shocks in housing boombust cycles, see the survey of Mian and Sufi (2018) and the references therein.
} 


\section{A SIMPLE REPRESENTATIVE-AGENT MODEL}

In this section, we provide a stylized representative-agent model to illustrate how housing demand shocks used in the macroeconomics literature drive the house price. To sharpen the exposition of our analysis, we focus on an endowment economy such that the house price does not interact with consumption and production. ${ }^{3}$

Following the literature, we assume that the economy has one unit of housing supply (e.g., the limit of land usable for housing). The representative household is endowed with $y_{t}$ units of consumption goods and has the expected utility function

$$
\mathbb{E}_{0} \sum_{t=0}^{\infty} \beta^{t}\left\{\log c_{t}+\varphi_{t} \frac{h_{t}^{1-\theta}}{1-\theta}\right\},
$$

where $c_{t}$ denotes consumption, $h_{t}$ housing, and $\varphi_{t}$ a housing demand shock - its micro foundation is a focus of this paper. The parameter $\beta \in(0,1)$ is the subjective discount factor and $\theta>0$ is a parameter that measures the curvature of the utility function with respect to housing services. Our analytical results depend on the value of $\theta$.

The household chooses consumption $\left(c_{t}\right)$, an additional house purchase $\left(h_{t}-h_{t-1}\right)$, and holdings of the risk-free bond $\left(b_{t}\right)$ to maximize the utility function (1) subject to the flow-of-funds constraint

$$
c_{t}+q_{t}\left(h_{t}-h_{t-1}\right) \leq y_{t}+\frac{b_{t}}{R_{t}}-b_{t-1}
$$

where $q_{t}$ is the house price and $R_{t}$ is the risk free interest rate, both prices taken as given by the household. The initial bond holdings $b_{-1}$ and the initial housings of $h_{-1}$ are also taken as given.

The optimizing decisions lead to the Euler equation for house purchases

$$
\frac{q_{t}}{c_{t}}=\beta \mathbb{E}_{t} \frac{q_{t+1}}{c_{t+1}}+\varphi_{t} h_{t}^{-\theta}
$$

and for bond holdings

$$
1=\beta R_{t} \mathbb{E}_{t} \frac{c_{t}}{c_{t+1}}
$$

A competitive equilibrium consists of sequences of allocations $\left\{c_{t}, b_{t}, h_{t}\right\}$ and prices $\left\{q_{t}, R_{t}\right\}$ such that (i) taking the prices as given, the allocations solve the household's utility maximization problem and (ii) the markets for goods, bond, and housing all clear: $c_{t}=y_{t}, b_{t}=0$, and $h_{t}=1$.

\footnotetext{
${ }^{3}$ The key insight about the role of housing demand shocks in driving the house price fluctuation carries over to a general environment with consumption and production (Iacoviello and Neri, 2010; Liu et al., 2013).
} 
Using the market clearing conditions for goods and housing, we can solve for the equilibrium house price:

$$
q_{t}=y_{t}\left[\mathbb{E}_{t} \sum_{j=0}^{\infty} \beta^{j} \varphi_{t+j}\right]
$$

The implicit rent is pinned down by the household's MRS between housing services and non-housing consumption, which is given by

$$
r_{h t}=\varphi_{t} y_{t}
$$

Thus, the price-to-rent ratio is given by

$$
\frac{q_{t}}{r_{h t}}=\frac{1}{\varphi_{t}} \mathbb{E}_{t} \sum_{j=0}^{\infty} \beta^{j} \varphi_{t+j}
$$

Eq. (5) reveals that the volatility of house prices stems primarily from the housing demand shock $\left(\varphi_{t}\right)$. Eq. (6) shows that this shock also drives rent fluctuations. Thus, the representative-agent model has difficulty in generating a large volatility of the price-to-rent ratio.

To illustrate this point in a concrete example, consider the stationary process for the housing demand shock

$$
\hat{\varphi}_{t}=\rho \hat{\varphi}_{t-1}+e_{t}
$$

where $\hat{\varphi}_{t} \equiv \log \frac{\varphi_{t}}{\varphi}$ denotes the log-deviation of the housing demand shock from its steady state value and $e_{t}$ is a white noise innovation to the shock. Log-linearizing equation (5) around the steady state and imposing the shock process in equation (8), we obtain

$$
\hat{q}_{t}=\hat{y}_{t}+(1-\beta) \mathbb{E}_{t}\left[\sum_{j=0}^{\infty} \beta^{j} \hat{\varphi}_{t+j}\right]=\hat{y}_{t}+\frac{1-\beta}{1-\beta \rho} \hat{\varphi}_{t},
$$

where $\hat{y}_{t}$ is a log-linearized process of $y_{t}$. The log-linearized solution for the rent is given by

$$
\hat{r}_{h t}=\hat{y}_{t}+\hat{\varphi}_{t}
$$

The log-linearized price-to-rent ratio becomes

$$
\hat{q}_{t}-\hat{r}_{h t}=-\frac{\beta(1-\rho)}{1-\beta \rho} \hat{\varphi}_{t} .
$$

There are two important facts contradicted by the implications of this representativeagent model. First, the model implies that the price-to-rent ratio falls when the house price rises, as shown by equation (11). In the data, however, the price-rent ratio are highly positively correlated with house prices (see Figures 1-2). 
Second, the model cannot generate a large volatility of the price-to-rent ratio as in the data. To illustrate this point, we keep the endowment constant so that $\hat{y}_{t}=0$. The model thus implies that

$$
\frac{\operatorname{STD}\left(\hat{q}_{t}\right)}{\operatorname{STD}\left(\hat{r}_{h t}\right)}=\frac{1-\beta}{1-\beta \rho}<1
$$

so that the house price is less volatile than the rent, opposite of the fact discussed above. We call these two counterfactual model implications the "price-rent" puzzle.

\section{A heterogenous-Agent Model of housing Demand}

In this section, we argue that the price-rent puzzle is a direct result of treating the housing demand shock as a reduced-form shock. To this end, we develop a simple heterogeneous-agent model with an idiosyncratic shock to the household' taste for housing services to (a) provide a microeconomic foundation for the housing demand shock and (b) illustrate that this micro foundation helps resolve the price-rent puzzle. Such idiosyncratic shocks are meant to capture potential heterogeneity in households' desires to purchase homes for reasons such as job relocations, schooling choices, and health care needs. To obtain the key insight, we simplify the model by postulating the existence of some implicit financial arrangement to insure non-housing consumption against realizations of idiosyncratic taste shocks. We also abstract from labor supply and capital investment decisions in this basic model. ${ }^{4}$

III.1. The model. Consider a large household family with a continuum of members. Each member has an idiosyncratic taste for housing services. The idiosyncratic shock $\varepsilon_{t}$ follows an i.i.d. process (across members and across time) drawn from the distribution $F(\cdot)$. Because of the complete insurance against non-housing consumption risks, all members enjoy the same consumption $c_{t}$. Housing services, however, must be indexed by $\varepsilon$. The expected utility function of the family is given by

$$
\mathbb{E}_{0} \sum_{t=0}^{\infty} \beta^{t}\left[\log c_{t}+\varphi \int_{0}^{\infty} \frac{\left[h_{t}\left(\varepsilon_{t}\right)\right]^{1-\theta}}{1-\theta} \varepsilon_{t} d F\left(\varepsilon_{t}\right)\right]
$$

where $h_{t}\left(\varepsilon_{t}\right)$ denotes the housing stock owned by the member with shock $\varepsilon_{t}$ and the parameter $\varphi$ measures the utility weight for housing. Note that $\varphi$ is constant so that there is no reduced-form aggregate housing demand shock in this heterogeneous-agent model. The parameter $\theta \geq 0$ is the relative risk aversion parameter with respect to housing services.

\footnotetext{
${ }^{4}$ See Appendix B for various generalizations of this stylized model.
} 
The resources available to the family at the beginning of period $t$ includes an exogenous labor income $y_{t}$ and the resale value of the existing housing stock, which is carried over from $t-1$ to $t$ by all members after paying off the matured debts for the family. The family uses these resources to fund consumption $c_{t}$ shared by all members and disperse the remaining funds $a_{t}$ equally among members for purchasing houses in the decentralized housing market. Since housing services are perfectly tradable across all family members, there is an equilibrium house price $q_{t}$.

The budget constraint faced by the family is

$$
c_{t}+a_{t}=y_{t}+q_{t} \int h_{t-1}\left(\varepsilon_{t-1}\right) d F\left(\varepsilon_{t-1}\right)-\int b_{t-1}\left(\varepsilon_{t-1}\right) d F\left(\varepsilon_{t-1}\right) .
$$

In the decentralized housing market, a family member with idiosyncratic shock $\varepsilon_{t}$ finances her new house purchase $q_{t} h_{t}\left(\varepsilon_{t}\right)$ through both internal funds $a_{t}$ and external borrowings $b_{t}\left(\varepsilon_{t}\right)$ at the interest rate $R_{t}$ :

$$
q_{t} h_{t}\left(\varepsilon_{t}\right) \leq a_{t}+\frac{b_{t}\left(\varepsilon_{t}\right)}{R_{t}} .
$$

As in Kiyotaki and Moore (1997), imperfect contract enforcement implies that the external debt cannot exceed a fraction of the collateral value:

$$
\frac{b_{t}\left(\varepsilon_{t}\right)}{R_{t}} \leq \kappa_{t} q_{t} h_{t}\left(\varepsilon_{t}\right)
$$

where $\kappa_{t} \in[0,1]$ represents an exogenous shock to the credit availability. We impose a constraint on short-selling the housing stock so that

$$
h_{t}\left(\varepsilon_{t}\right) \geq 0
$$

Combining the flow-of-funds constraint (15) and the collateral constraint (16) gives

$$
q_{t} h_{t}\left(\varepsilon_{t}\right) \leq \frac{a_{t}}{1-\kappa_{t}}
$$

As $\kappa_{t} \rightarrow 1$, there will be no limit on house spendings. In what follows, we assume $\kappa_{t}<1$ to exclude this extreme case.

The family chooses $c_{t}$ and $a_{t}$ and each member with $\varepsilon_{t}$ chooses $h_{t}\left(\varepsilon_{t}\right)$ and $b_{t}\left(\varepsilon_{t}\right)$ to maximize the utility function (13), subject to the family budget constraint (14) as well as the individual member's flow-of-funds constraint (15), borrowing constraint (16), and short-sell constraint (17). The initial values of $b_{-1}$ and $h_{-1}$ and the prices $q_{t}$ and $R_{t}$ are taken as given.

Denote by $\lambda_{t}, \eta_{t}\left(\varepsilon_{t}\right), \pi_{t}\left(\varepsilon_{t}\right)$ and $\mu_{t}\left(\varepsilon_{t}\right)$ the Lagrangian multiplers associated with constraints $(14),(15),(16)$, and (17) respectively. In the discussions below, we consider a general case with $\theta>0$ so that the short-sell constraint (17) is not binding, 
implying that $\mu_{t}\left(\varepsilon_{t}\right)=0$. We leave the special case $\theta=0$ to Section $\mathrm{V}$ when we study a numerical example.

The first-order condition with respect to $a_{t}$ is

$$
\lambda_{t}=\int \eta_{t}\left(\varepsilon_{t}\right) d F\left(\varepsilon_{t}\right)
$$

An extra unit of funds allocated to family members for purchasing new houses reduces family consumption by one unit with the utility cost $\lambda_{t}$. The utility gain from this allocation is the average shadow value of newly purchased houses across all members.

The first order condition with respect to $h_{t}\left(\varepsilon_{t}\right)$ is

$$
\eta_{t}\left(\varepsilon_{t}\right) q_{t}=\varphi \varepsilon_{t}\left[h_{t}\left(\varepsilon_{t}\right)\right]^{-\theta}+\beta \mathbb{E}_{t} \lambda_{t+1} q_{t+1}+\kappa_{t} q_{t} \pi_{t}\left(\varepsilon_{t}\right)
$$

For member $\varepsilon$, the utility cost of purchasing a unit of housing is $q_{t} \eta\left(\varepsilon_{t}\right)$. The extra unit of housing yields the utility gain $\varphi \varepsilon_{t}\left[h_{t}\left(\varepsilon_{t}\right)\right]^{-\theta}$ from housing services. The unit of housing can be sold at the price $q_{t+1}$ next period, yielding the present value $\beta \mathbb{E}_{t} \lambda_{t+1} q_{t+1}$. Having an extra unit of housing also increases the collateral value and helps relax the collateral constraint, with the shadow utility value of $\kappa_{t} q_{t} \pi_{t}\left(\varepsilon_{t}\right)$. The optimal choice of $h_{t}\left(\varepsilon_{t}\right)$ implies that the marginal cost must equal the sum of these marginal benefits.

The first-order condition with respect to $b_{t}\left(\varepsilon_{t}\right)$ is

$$
\eta_{t}\left(\varepsilon_{t}\right)=\beta R_{t} \mathbb{E}_{t} \lambda_{t+1}+\pi_{t}\left(\varepsilon_{t}\right)
$$

Borrowing an extra unit of funds yields the utility value $\eta_{t}\left(\varepsilon_{t}\right)$. The family repays the debt next period at the interest rate $R_{t}$, with the present value of the utility cost of $\beta R_{t} \mathbb{E}_{t} \lambda_{t+1}$. The increase in borrowings tightens the collateral constraint with the utility cost $\pi_{t}\left(\varepsilon_{t}\right)$. For an optimal choice of $b_{t}\left(\varepsilon_{t}\right)$, the utility gain must equal to the sum of these two utility costs.

III.2. Equilibrium. A competitive equilibrium is a collection of prices $\left\{q_{t}, R_{t}\right\}$ and allocations $\left\{c_{t}, a_{t}, h_{t}\left(\varepsilon_{t}\right), b_{t}\left(\varepsilon_{t}\right)\right\}$ such that

(1) taking the prices as given, the allocations solve the household's utility maximizing problem;

(2) the markets for goods, housing, and credit all clear so that

$$
\begin{aligned}
c_{t} & =y_{t} \\
\int h_{t}(\varepsilon) d F(\varepsilon) & =1 \\
\int b_{t}(\varepsilon) d F(\varepsilon) & =0 .
\end{aligned}
$$




\section{Characterizing the Equilibrium}

We now characterize the equilibrium of the heterogeneous-agent model.

IV.1. The cutoff point among heterogeneous agents. Family members with sufficiently high marginal utility (i.e., high $\varepsilon_{t}$ ) faces binding borrowing constraints. Thus, we conjecture that there exists a cutoff point $\varepsilon_{t}^{*}$ in the support of the distribution $F(\varepsilon)$ such that the borrowing constraints are binding if and only if $\varepsilon t>\varepsilon_{t}^{*}$. Lemma 1 below gives the solution for the equilibrium housing demand $h_{t}\left(\varepsilon_{t}\right)$ as well as the cutoff point $\varepsilon_{t}^{*}$.

Lemma 1. There exists a cutoff point $\varepsilon_{t}^{*}$ in the support of the distribution $F(\varepsilon)$, such that

$$
h_{t}\left(\varepsilon_{t}\right)=\min \left\{\left(\frac{\varepsilon_{t}}{\varepsilon_{t}^{*}}\right)^{\frac{1}{\theta}}, 1\right\} \frac{1}{1-\kappa_{t}} .
$$

The cutoff point $\varepsilon_{t}^{*}$ is determined by

$$
\int \min \left\{1,\left(\frac{\varepsilon}{\varepsilon_{t}^{*}}\right)^{\frac{1}{\theta}}\right\} f(\varepsilon) d \varepsilon=1-\kappa_{t} .
$$

Proof. If $\varepsilon_{t} \geq \varepsilon_{t}^{*}$, then the borrowing constraint (16) is binding. The flow-of-funds constraint (15) implies that

$$
q_{t} h_{t}\left(\varepsilon_{t}\right)=a_{t}+\frac{b_{t}\left(\varepsilon_{t}\right)}{R_{t}}=a_{t}+\kappa_{t} q_{t} h_{t}\left(\varepsilon_{t}\right) .
$$

Integrating over $\varepsilon$ and imposing the market clearing conditions lead to $a_{t}=q_{t}$. Substituting out $a_{t}$ in Eq. (26), we obtain

$$
h_{t}\left(\varepsilon_{t}\right)=\frac{a_{t}}{q_{t}\left(1-\kappa_{t}\right)}=\frac{1}{1-\kappa_{t}} .
$$

If $\varepsilon_{t}<\varepsilon_{t}^{*}$, then $\pi_{t}\left(\varepsilon_{t}\right)=0$. From Eq. (19) and (20), we have

$$
\varphi \varepsilon_{t}\left[h_{t}\left(\varepsilon_{t}\right)\right]^{-\theta}=\varphi \varepsilon_{t}^{*}\left[h_{t}\left(\varepsilon_{t}^{*}\right)\right]^{-\theta}=\varphi \varepsilon_{t}^{*}\left(\frac{1}{1-\kappa_{t}}\right)^{-\theta} .
$$

Eq. (24) follows immediately from Eq. (27) and (28).

Integrating Eq. (24) over $\varepsilon_{t}$ and imposing the housing market clearing condition (22), we obtain Eq (25).

The proposition below establishes that, under some mild restriction on the distribution of $\varepsilon$, the cutoff $\varepsilon_{t}^{*}$ increases with $\kappa_{t}$. Thus, a credit-supply expansion leads to fewer credit-constrained agents. 
Proposition 1. Assume that the support of the distribution of $\varepsilon_{t}$ is $[0, \bar{\varepsilon}]$ and that $\kappa_{t}$ is bounded above by $\bar{\kappa} \equiv 1-\int_{0}^{\bar{\varepsilon}}\left(\frac{\varepsilon}{\bar{\varepsilon}}\right)^{\frac{1}{\theta}} f(\varepsilon) d \varepsilon$ such that $\varepsilon^{*}\left(\kappa_{t}\right) \in(0, \bar{\varepsilon})$ for $\kappa_{t} \in(0, \bar{\kappa})$. Then we have $\frac{\partial \varepsilon^{*}\left(\kappa_{t}\right)}{\partial \kappa_{t}}>0$.

Proof. For any $\tilde{\varepsilon} \in(0, \bar{\varepsilon})$,

$$
\begin{gathered}
\lim _{\tilde{\varepsilon} \rightarrow \varepsilon_{\max }} \int_{0}^{\bar{\varepsilon}} \min \left\{1,\left(\frac{\varepsilon}{\tilde{\varepsilon}}\right)^{\frac{1}{\theta}}\right\} f(\varepsilon) d \varepsilon=1-\bar{\kappa}<1-\kappa, \\
\lim _{\tilde{\varepsilon} \rightarrow 0} \int_{0}^{\bar{\varepsilon}} \min \left\{1,\left(\frac{\varepsilon}{\tilde{\varepsilon}}\right)^{\frac{1}{\theta}}\right\} f(\varepsilon) d \varepsilon=1>1-\kappa .
\end{gathered}
$$

By the Intermediate Value Theorem, equation (25) has an interior solution $\varepsilon^{*}\left(\kappa_{t}\right) \in$ $(0, \bar{\varepsilon})$. Since the left-hand side of the equation strictly decreases with $\varepsilon_{t}^{*}$ and the right-hand side strictly decreases with $\kappa_{t}$, it follows that $\frac{\partial \varepsilon^{*}\left(\kappa_{t}\right)}{\partial \kappa_{t}}>0$.

IV.2. Aggregate housing demand and the house price. Integrating equation (19) across $\varepsilon_{t}$, we obtain the expression for the house price

$$
q_{t} \lambda_{t}=\mathbb{E}_{t} \beta \lambda_{t+1} q_{t+1}+\varphi \int_{0}^{\bar{\varepsilon}}\left[h_{t}\left(\varepsilon_{t}\right)\right]^{-\theta} \varepsilon d F(\varepsilon)+\kappa_{t} q_{t} \int_{\varepsilon_{t}^{*}}^{\bar{\varepsilon}} \pi_{t}(\varepsilon) d F(\varepsilon) \text {, for } \theta>0
$$

where the first integral on the right-hand side of the equation is the average marginal utility (the rent) and the second integral is the liquidity premium, which is positive if and only if $\varepsilon_{t}>\varepsilon_{t}^{*}$. This result is formally stated in the following proposition.

Proposition 2. The equilibrium house price satisfies the Euler equation

$$
q_{t} \lambda_{t}=\mathbb{E}_{t} \beta \lambda_{t+1} q_{t+1}+\xi\left(\kappa_{t}\right)
$$

where

$$
\xi\left(\kappa_{t}\right) \equiv \underbrace{\varphi\left(1-\kappa_{t}\right)^{\theta} \mathbb{E} \max \left\{\varepsilon, \varepsilon_{t}^{*}\right\}}_{\text {Average marginal utility }}+\underbrace{\frac{\varphi\left(1-\kappa_{t}\right)^{\theta}}{1-\kappa_{t}} \int_{\varepsilon_{t}^{*}}^{\bar{\varepsilon}}\left(\varepsilon-\varepsilon_{t}^{*}\right) d F(\varepsilon)}_{\text {Liquidity premium } \Pi_{t}},
$$

Proof. See Appendix C.

The following proposition, built on Proposition 2, provides a microeconomic foundation for the reduced-form housing demand shock.

Proposition 3. If $\xi\left(\kappa_{t}\right)=\varphi_{t}$, then the equilibrium house price in the heterogeneousagent model coincides with that in the representative agent model.

Proof. The housing Euler equation (30) in the heterogeneous-agent economy is

$$
\frac{q_{t}}{c_{t}}=\beta \mathbb{E}_{t} \frac{q_{t+1}}{c_{t+1}}+\xi\left(\kappa_{t}\right)
$$


The housing Euler equation in the representative-agent model, represented by (3), is rewritten for referencing convenience:

$$
\frac{q_{t}}{c_{t}}=\beta \mathbb{E}_{t} \frac{q_{t+1}}{c_{t+1}}+\varphi_{t} h_{t}^{-\theta}
$$

In equilibrium, the housing market clears so that $h_{t}=1$. Thus, if $\xi\left(\kappa_{t}\right)=\varphi_{t}$, the housing Euler equations in the two different economies are identical. Since goods market clearing implies that $c_{t}=y_{t}$ in both models, the equilibrium house price is also identical.

Clearly from Proposition 3, aggregate housing demand is a function of credit supply $\kappa_{t} \cdot{ }^{5}$ Equation (31) shows that aggregate housing demand and the house price depend on two forces: (i) the average MRS between housing services and non-housing consumption across all agents (the implicit rent) and (ii) the liquidity premium deriving from binding collateral constraints for a subset of agents with high MRSs. It is the liquidity premium that drives a wedge between price and rent, creating room for potentially large fluctuations in the price-to-rent ratio with changes in the leverage condition.

IV.3. The relation between credit supply and the house price and rent: the role of the marginal agent. The house price in our model always satisfies the Euler equation for the marginal agent, who faces the idiosyncratic shock $\varepsilon_{t}^{*}$ and is not credit constrained:

$$
q_{t} \frac{\eta_{t}^{*}}{\lambda_{t}}=\mathbb{E}_{t} \beta \frac{\lambda_{t+1}}{\lambda_{t}} q_{t+1}+\underbrace{\frac{\varphi}{\lambda_{t}} \varepsilon_{t}^{*}\left(1-\kappa_{t}\right)^{\theta}}_{M R S_{t}^{*}}
$$

where $\eta_{t}^{*}=R_{t} \mathbb{E}_{t} \beta \frac{\lambda_{t+1}}{\lambda_{t}}$ is an increasing function of the interest rate $R_{t}$ and $M R S_{t}^{*}$ denotes the marginal agent's MRS between housing services and non-housing consumption. For any given interest rate, the house price increases with $M R S_{t}^{*}$.

To see how credit supply affects the house price through $M R S^{*}$, consider the cumulative density function for the idiosyncratic shock

$$
F(\varepsilon)=\left(\frac{\varepsilon}{\bar{\varepsilon}}\right)^{\eta}
$$

where $\eta>0$ is the shape parameter and we normalize the scale parameter $\bar{\varepsilon}=\frac{1+\eta}{\eta}$ so that the mean of the idiosyncratic shock is one.

\footnotetext{
${ }^{5}$ In general, any shock that shifts the cutoff point $\varepsilon_{t}^{*}$ would shift the aggregate housing demand, thereby driving the house price fluctuation. We focus on credit supply shocks because this mechanism is supported by empirical evidence discussed in Section VI.
} 
Proposition 4. Assume that the idiosyncratic shock follows the distribution (34). The marginal agent's MRS increases with $\kappa_{t}$ if and only if $\theta<\frac{1-\kappa_{t}}{\eta \kappa_{t}}$.

Proof. Under the distribution function (34), the cutoff point is given by

$$
\varepsilon_{t}^{*}=\left[(1+\theta \eta) \kappa_{t}\right]^{\frac{1}{\eta}} \bar{\varepsilon}
$$

Using the expression for $M R S_{t}^{*}$ in Eq (33), we obtain the elasticity of $M R S_{t}^{*}$ with respect to $\kappa_{t}$ as

$$
e_{M R S^{*}, \kappa} \equiv \frac{\partial M R S_{t}^{*}}{\partial \kappa_{t}} \frac{\kappa_{t}}{M R S_{t}^{*}}=\frac{1}{\eta}-\theta \frac{\kappa_{t}}{1-\kappa_{t}} .
$$

Hence,

$$
e_{M R S^{*}, \kappa}>0 \text { if and only if } \theta<\frac{1-\kappa_{t}}{\eta \kappa_{t}}
$$

Proposition 4 shows that the relation between the marginal agent's MRS and credit supply is non-monotonic, depending on $\theta$, the value of the agent's risk aversion with respect to housing services.

An increase in credit supply has two opposing effects on the marginal agent's MRS. First, according to Proposition 1, an increase in $\kappa_{t}$ raises the cutoff point $\varepsilon_{t}^{*}$, and the new marginal agent has a higher MRS than in the original equilibrium (the extensive margin). All else equal, this extensive-margin effect raises the house price. However, a relaxation of the credit constraint also enables the new marginal agent to enjoy more housing services, lowering her MRS through the diminishing marginal utility (the intensive margin). The intensive-margin effect reduces the house price.

The net effect depends on how risk-averse the agent is. If the marginal agent has a sufficiently low risk aversion with respect to housing services (a low value of $\theta$ ), the extensive-margin effect dominates through a shift of the cutoff point and an increase in $\kappa_{t}$ raises the housing demand and the house price. If the marginal agent has a high risk aversion, the intensive-margin effect dominates through the diminishing marginal utility and an increase in $\kappa_{t}$ reduces the housing demand and the house price.

No matter what value $\theta$ is, however, the relation between the rental rate and credit availability $\left(\kappa_{t}\right)$ remains ambiguous. ${ }^{6}$ Thus, we define the implicit rent as the average

\footnotetext{
${ }^{6}$ We abstract from an explicit rental market to simplify the analysis. We discuss an extension of the model with an explicit rental market in Appendix D, where we show that that the market rental rate equals the average MRS between housing services and non-housing consumption across all agents.
} 
MRS across all agents:

$$
r_{h t}=\frac{\varphi}{\lambda_{t}} \int_{0}^{\bar{\varepsilon}} \varepsilon_{t}\left[h_{t}\left(\varepsilon_{t}\right)\right]^{-\theta} d F\left(\varepsilon_{t}\right) .
$$

Since high-MRS agents face binding borrowing constraints, a change in credit availability $\left(\kappa_{t}\right)$ affects the marginal utilities of those agents and thus the rent.

Proposition 5. For $\theta>0$, the rent is given by

$$
r_{h t}=\frac{\varphi}{\lambda_{t}}\left(1-\kappa_{t}\right)^{\theta} \mathbb{E} \max \left\{\varepsilon, \varepsilon_{t}^{*}\right\}
$$

The effect of a change in $\kappa_{t}$ on $r_{h t}$ is ambiguous.

Proof. In $(38),\left(1-\kappa_{t}\right)^{\theta}$ decreases with $\kappa_{t}$ while $\mathbb{E} \max \left\{\varepsilon, \varepsilon_{t}^{*}\right\}$ increases with $\kappa_{t}$, because $\varepsilon_{t}^{*}$ itself increases with $\kappa_{t}$ according to Proposition 1. Thus, the effect on $r_{h t}$ is ambiguous.

\section{A CLOSED-FORM EXAMPLE}

In this section, we obtain closed-form solutions for the house price, the rent, and the price-to-rent ratio by considering a special case with $\theta=0$ and using the distribution function specified in equation (34). We use this example to illustrate the mechanism through which credit market conditions can affect the house price and the price-to-rent ratio.

With $\theta=0$, the no-short-sale restriction (17) is binding for the agents with low realizations of $\varepsilon$. The housing Euler equation (29) becomes

$$
q_{t} \lambda_{t}=\mathbb{E}_{t} \beta \lambda_{t+1} q_{t+1}+\varphi \int_{0}^{\bar{\varepsilon}} \varepsilon d F(\varepsilon)+\kappa_{t} q_{t} \int_{\varepsilon_{t}^{*}}^{\bar{\varepsilon}} \pi_{t}(\varepsilon) d F(\varepsilon)+\int_{0}^{\bar{\varepsilon}} \mu_{t}(\varepsilon) d F(\varepsilon),
$$

where the Lagrangian multiplier $\mu_{t}(\varepsilon)$ for the no-short-sale restriction is positive if and only if $h_{t}(\varepsilon)=0$. Specifically, it is given by $\mu_{t}(\varepsilon)=\varphi \max \left\{\varepsilon_{t}^{*}-\varepsilon, 0\right\}$.

Equation (39) can be written in the compact form

$$
q_{t} \lambda_{t}=\mathbb{E}_{t} \beta \lambda_{t+1} q_{t+1}+\xi\left(\kappa_{t}\right)
$$

where

$$
\begin{aligned}
\xi\left(\kappa_{t}\right) & \equiv \underbrace{\varphi \mathbb{E}(\varepsilon)}_{\text {Average marginal utility }}+\kappa_{\text {Liquidity premium } \Pi_{t}}^{\frac{1}{1-\kappa_{t}} \int_{\varepsilon_{t}^{*}}^{\bar{\varepsilon}} \varphi\left(\varepsilon_{t}-\varepsilon_{t}^{*}\right) d F\left(\varepsilon_{t}\right)}+\underbrace{\varphi \int_{0}^{\varepsilon_{t}^{*}}\left(\varepsilon_{t}^{*}-\varepsilon_{t}\right) d F\left(\varepsilon_{t}\right)}_{\text {Option value } \mathcal{O}_{t}} . \\
& =\varphi+\varphi \kappa_{t}\left(1-\kappa_{t}\right)+\varphi \kappa_{t}^{2}=\varphi\left(1+\kappa_{t}\right) .
\end{aligned}
$$


Thus, housing demand $\xi\left(\kappa_{t}\right)$ increases with $\kappa_{t}$, implying that the house price increases with $\kappa_{t}$ as well. However, the average marginal utility of housing $(\varphi)$ is independent of $\kappa_{t}$, as is the rent.

This example illustrates that our model is capable of generating a much larger fluctuation in the house price than in the rent. Consequently, the price-to-rent ratio is as volatile as the house price and the two variables comove. This result from the heterogeneous-agent model stands in sharp contrast to that from the representativeagent model discussed in Section II, which fails to generate the observed large fluctuation in the price-to-rent ratio and the observed comovement between the house price and the price-to-rent ratio.

\section{EMPIRICAL EVIDENCE}

In previous sections, we develop a theoretical model to show that a credit supply shock can have a large impact on the house price, but not on rent. Therefore, the model predicts that a boom in credit supply should raise both the house price and the price-to-rent ratio. In this section, we present relevant empirical evidence to support the model's prediction.

To obtain dynamic responses of the house price, the rent, and the price-to-rent ratio to a credit supply shock, we follow the approach of Mian et al. (2017) and identify a credit supply shock as an acceleration in credit growth during periods when mortgage spreads are low. We use two distinct datasets: (i) international data and (2) U.S. regional data. For international data from 1965 to 2013, we use an unbalanced panel of 25 advanced economies. We follow Mian et al. (2017) and measure credit growth by year-over-year changes in the ratio of household debt to GDP in each country. The mortgage spread for each country is the spread between the mortgage interest rate and the 10-year sovereign bond yield.

For U.S. regional data from 1978 to 2017, we use an unbalanced panel of 21 MSAs in the United States. Credit growth is measured by year-over-year changes in the ratio of mortgage loans to the house price in each MSA, and the mortgage spread is the effective mortgage interest rate minus the 10 -year U.S. Treasury yield. ${ }^{7}$

\footnotetext{
${ }^{7}$ Data details and summary statistics are presented in Tables S1 and S2 of Appendix E.
} 
Using each panel dataset, we estimate the dynamic responses of housing-market variables (price, rent, price-rent ratio) to a credit supply shock using the localprojection approach of Jorda (2005). Specifically, we estimate the instrumentalvariable local-projection (IV-LP) model

$$
\log Y_{i, t+h}-\log Y_{i t}=\alpha_{0}^{h}+\sum_{j=0}^{8} \beta_{j}^{h} \Delta D_{i, t-j}^{H H}+\gamma_{i}^{h}+u_{i, t+h}^{h}
$$

where $Y_{i, t}$ denotes a housing-market variable of interest in country or region $i$ and year $t, \Delta D_{i t}^{H H}$ denotes a credit growth rate in country or region $i$ from $t-1$ to $t, \gamma_{i}^{h}$ captures the country/region fixed effect, and $u_{i, t+h}^{h}$ is a regression residual. The parameters $\alpha_{0}^{h}$ and $\beta_{j}^{h}$ are common for all countries or regions. Following Mian et al. (2017), we instrument credit growth by a dummy variable that equals one if the mortgage spread is below the median and zero otherwise. The F-statistics from the first-stage regressions suggest that we do not have a weak-instrument problem; the instrumental variable (the mortgage spread dummy) is highly and positively correlated with the variable of credit growth for both international and regional samples (Table 1).

Figure 3 displays the estimated dynamic responses of house price and rent to an expansionary credit supply shock and Figure 4 displays the responses of the priceto-rent ratio. The left column of both figures uses the cross-country data and the right column uses the U.S. MSA data. In both cases, an expansionary credit supply shock leads to a large, persistent, and statistically significant increases in the house price. One percentage-point increase in credit supply growth leads to an increase of approximately 7.5 percentage points in the house price at its peak. This finding is consistent with what is found in the literature (Mian et al., 2017; Jordà et al., 2016). By contrast, the rent responses to the credit supply shock is small and statistically insignificant (middle panels of Figure 3). The estimated rent responses from the MSA data become marginally significant after 3 years following the impact of the shock, but the magnitude of the rent response is small compared with the house price response. As a result, the credit supply shock leads to a large and persistent increase in the price-to-rent ratio (Figure 4). These empirical findings lend support to our theoretical prediction that a credit supply shock can drive large comovements between house price and price-to-rent ratio.

\section{CONCLUSION}

The standard macroeconomic models that rely on reduced-form housing demand shocks have difficulties in generating the observed large fluctuation of both the house 
price and the price-to-rent ratio. We develop a heterogeneous-agent model with credit constraints and build a microeconomic foundation of aggregate housing demand shocks. Since agents with idiosyncratic shocks have different marginal utilities of housing services, a subset of high-marginal utility agents face binding credit constraints, giving rise to an endogenous liquidity premium. The liquidity premium drives a wedge between the house price and the rent, allowing a credit supply expansion to generate a simultaneous increase in both the house price and the price-to-rent ratio.

Our model's main prediction that a credit supply shock has a large impact on the house price but not on the rent is supported by cross-country and cross-MSA evidence. Understanding the microeconomic forces that underpin aggregate housing demand shocks and the price-to-rent fluctuation is a critical first step for contemplating appropriate policy interventions in the housing market. We hope that our work contributes to this important research area. 
TABLE 1. First-stage regression for the IV-LP estimation

\begin{tabular}{|c|c|c|}
\hline & $\begin{array}{l}\text { International sample } \\
\qquad(1)\end{array}$ & $\begin{array}{c}\text { MSA sample } \\
(2)\end{array}$ \\
\hline \multirow{2}{*}{$I_{t}^{M S}$} & $0.75^{* * *}$ & $0.48^{* *}$ \\
\hline & $(0.23)$ & $(0.21)$ \\
\hline \multirow{2}{*}{$\Delta D_{t-1}^{H H}$} & $0.38^{* * *}$ & $-0.13^{* * *}$ \\
\hline & $(0.06)$ & $(0.04)$ \\
\hline \multirow[t]{2}{*}{$\Delta D_{t-2}^{H H}$} & 0.04 & -0.04 \\
\hline & $(0.05)$ & $(0.05)$ \\
\hline \multirow{2}{*}{$\Delta D_{t-3}^{H H}$} & $0.09^{* *}$ & $-0.17^{* * *}$ \\
\hline & $(0.04)$ & $(0.05)$ \\
\hline \multirow{2}{*}{$\Delta D_{t-4}^{H H}$} & 0.09 & $-0.25 * * *$ \\
\hline & $(0.08)$ & $(0.03)$ \\
\hline \multirow[t]{2}{*}{$\Delta D_{t-5}^{H H}$} & -0.11 & -0.07 \\
\hline & $(0.11)$ & $(0.05)$ \\
\hline \multirow[t]{2}{*}{$\Delta D_{t-6}^{H H}$} & 0.03 & $-0.09^{* *}$ \\
\hline & $(0.08)$ & $(0.03)$ \\
\hline \multirow[t]{2}{*}{$\Delta D_{t-7}^{H H}$} & $-0.15^{* *}$ & 0.006 \\
\hline & $(0.05)$ & $(0.03)$ \\
\hline \multirow[t]{2}{*}{$\Delta D_{t-8}^{H H}$} & $-0.15^{* * *}$ & $-0.13^{* * *}$ \\
\hline & $(0.05)$ & $(0.03)$ \\
\hline Observations & 451 & 558 \\
\hline F-Stat & 32.48 & 34.50 \\
\hline
\end{tabular}

Note: The table displays the first-stage regression results for the local-projection regression specified in (41). With international data (Column (1)), the table reports the regression of a year-over-year change in the ratio of household debt to GDP in country $i$ and year $t$ on its own lags and the instrumental variable, which is the mortgage spread dummy $I_{i t}^{M S}$ that equals one if the mortgage spread is below its median and zero otherwise. With U.S. regional data (Column (2)), the table reports the regression of a year-over-year change in the ratio of mortgage loans to the house price in region (MSA) $i$ and year $t$ on its own lags and the mortgage spread dummy. 


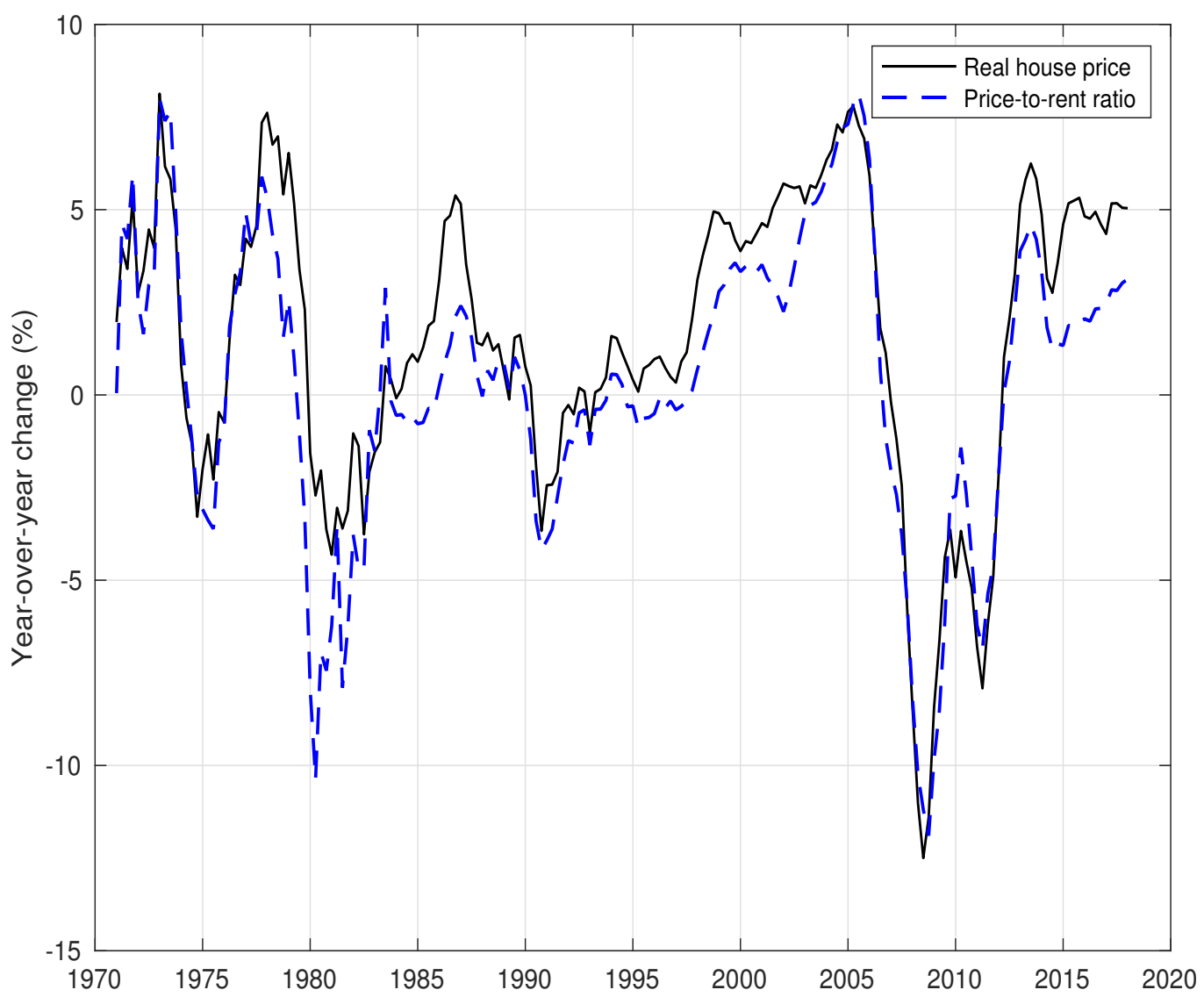

FIGURE 1. The real house price and the price-to-rent ratio in the United States. Data source: Haver Analytics and OECD. 

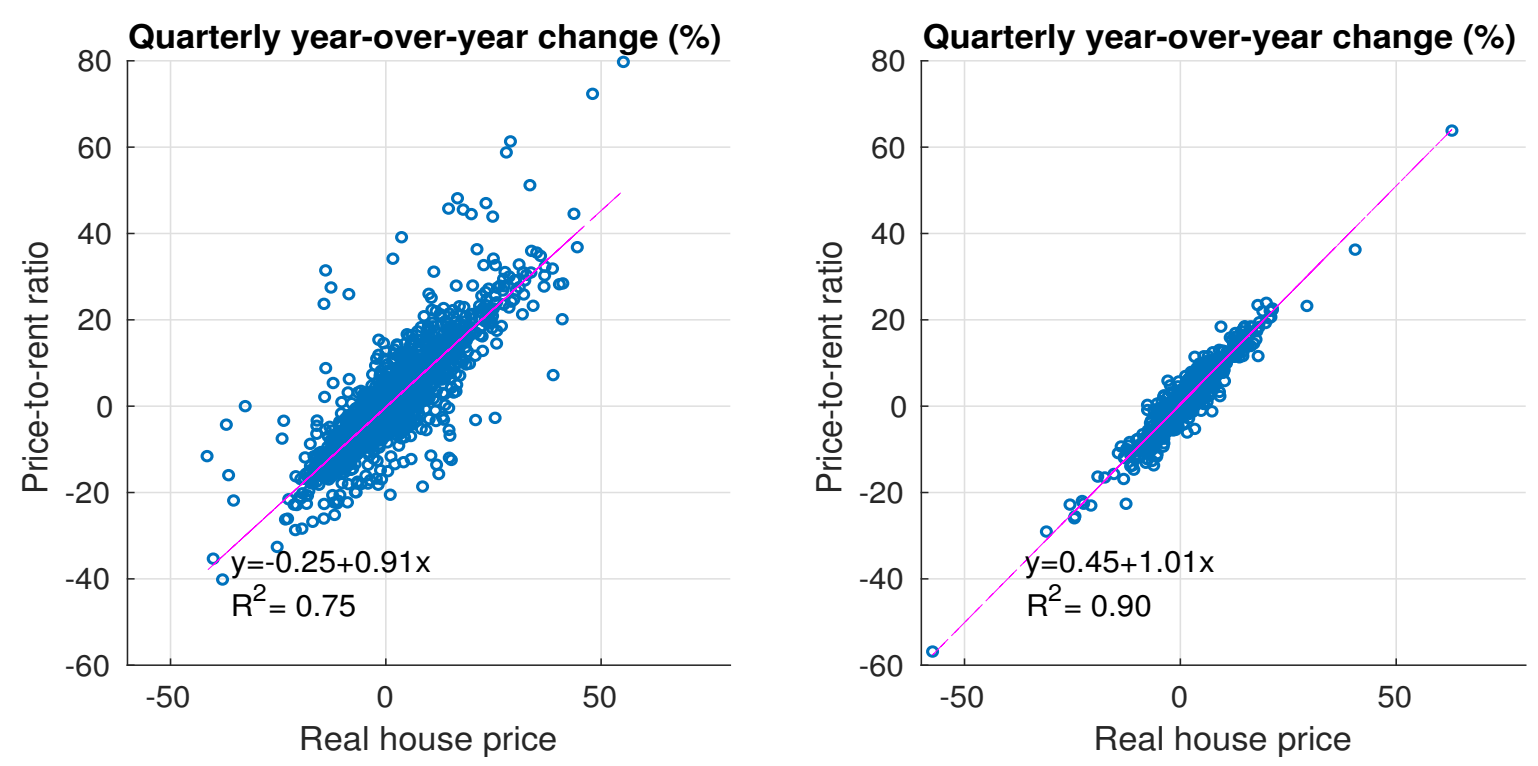

Figure 2. The real house price and the price-to-rent ratio in OECD countries (left panel) and in U.S. MSA regions (right panel). Data source: see Appendix E. 

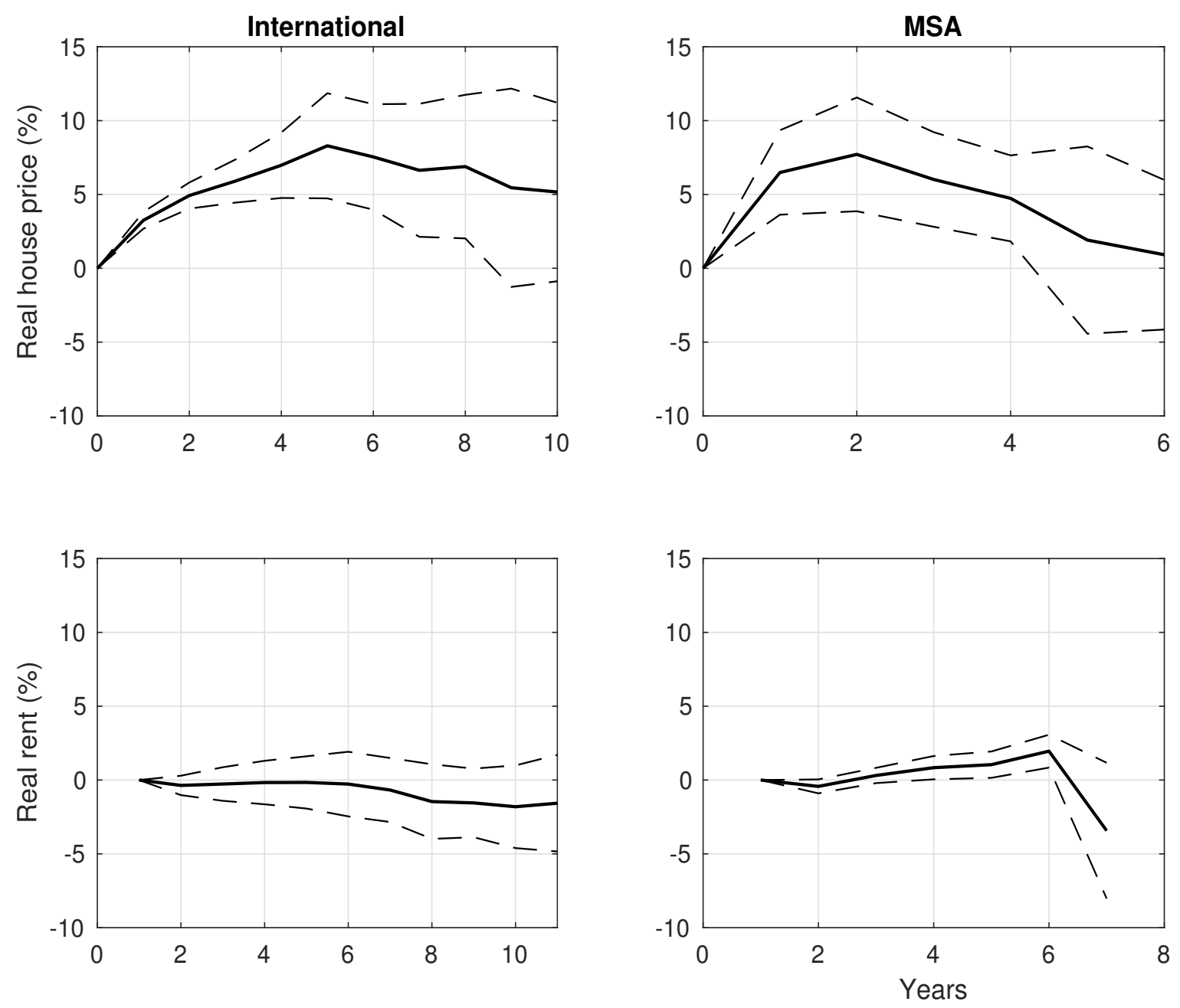

Figure 3. The dynamic responses of the house price and rent to an expansionary credit supply shock. The left column ("International") displays the responses estimated with the data from 25 OECD economies. The right column ("MSA") displays the responses estimated with the data from 21 U.S. MSAs. The solid line in each panel reports the point estimate of the dynamic responses of each variable to an increase in credit supply with the local-projection approach of Jorda (2005); the two dashed lines display one-standard-deviation confidence bands of the estimated responses. 

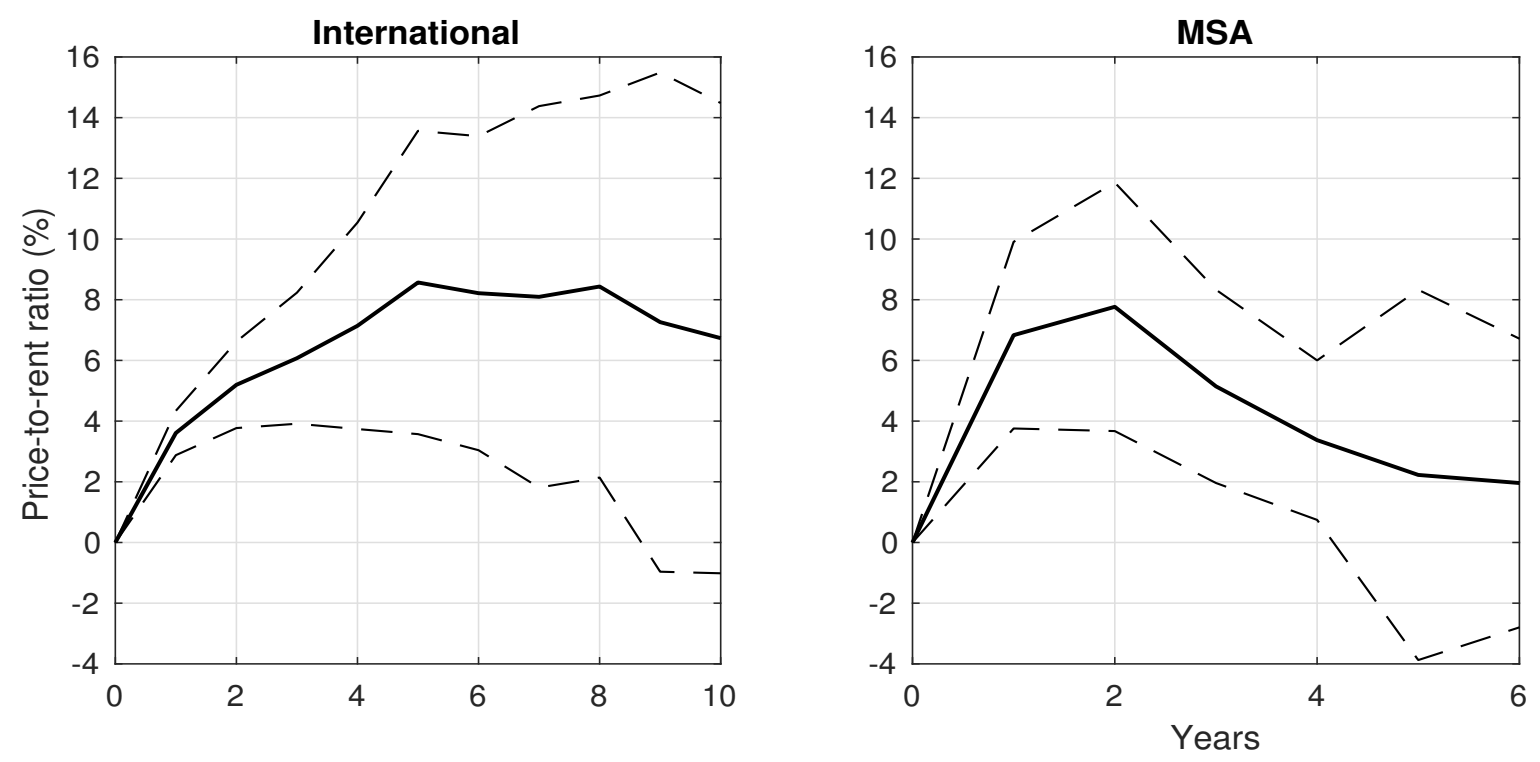

FiguRE 4. The dynamic responses of the price-to-rent ratio to an expansionary credit supply shock. The left column ("International") displays the responses estimated with the data from 25 OECD economies. The right column ("MSA") displays the responses estimated with the data from 21 U.S. MSAs. The solid line in each panel reports the point estimate of the dynamic responses of each variable to an increase in credit supply with the local-projection approach of Jorda (2005); the two dashed lines display one-standard-deviation confidence bands of the estimated responses. 


\section{REFERENCES}

Davis, M. A. And J. Heathcote (2007): "The Price and Quantity of Residential Land in the United States," Journal of Monetary Economics, 54, 2595-2620.

Dong, F. And Y. Wen (2019): "Long and Plosser meet Bewley and Lucas," Journal of Monetary Economics, forthcoming.

Favilukis, J., S. C. Ludvigson, And S. van Nieuwerburgh (2016): "The Macroeconomic Effects of Housing Wealth, Housing Finance, and Limited RiskSharing in General Equilibrium," Journal of Political Economy, 125, 140-223.

IACOVIEllo, M. AND S. NeRI (2010): "Housing Market Spillovers: Evidence from an Estimated DSGE Model," American Economic Journal: Macroeconomics, 2.

JordA, O. (2005): "Estimation and Inference of Impulse Responses by Local Projections," American Economic Review, 95, 161-182.

Jordà, O., M. Schularick, And A. M. TAYlor (2016): "The Great Mortgaging: Housing Finance, Crises and Business Cycles," Economic Policy, 107-152.

Kaplan, G., K. Mitman, And G. Violante (2017): "The Housing Boom and Bust: Model Meets Evidence," Unpublished Manuscript.

Kiyotaki, N. And J. Moore (1997): "Credit Cycles," Journal of Political Economy, 105, 211-248.

Lagos, R. And R. Wright (2005): "A Unified Framework for Monetary Theory and Policy Analysis," Journal of Political Economy, 113, 463-484.

Landvoigt, T., M. Piazzesi, And M. Schneider (2015): "The Housing Market(s) of San Dieg," American Economic Review, 105, 1371-1407.

LiU, Z., P. Wang, And T. Zha (2013): "Land-Price Dynamics and Macroeconomic Fluctuations," Econometrica, 81.

Mian, A. AND A. Sufi (2018): "Finance and Business Cycles: The Credit-Driven Household Demand Channel," Journal of Economic Perspectives, 32, 31-58.

Mian, A., A. Sufi, And E. Verner (2017): "Household Debt and Business Cycles Worldwide," Quarterly Journal of Economics, 132, 1755-1817.

Wen, Y. (2009): "An Analytical Approach to Buffer-Stock Saving under Borrowing Constraints," Federal Reserve Bank of St. Louis Working Paper 2009-026B. (2015): "Money, Liquidity, and Welfare," European Economic Review, 76, 124. 
The appendices contain a proof to Proposition 2 in the main text (Appendix C), some details of the data used in our empirical analysis (Appendix E), and several variations of the baseline heterogeneous-agent model (Appendix A, B, and D). All labels for equations, figures, tables, definitions, and propositions begin with S, standing for supplement to the main text.

\section{Appendix A. Heterogeneity in income}

In our benchmark model, we assume that the source of heterogeneity lies in the agent's tastes for housing. Idiosyncratic taste shocks give rise to differences in the marginal utility of housing across agents. Our framework with heterogenous marginal utilities, combined with credit constraints, provides a microeconomic foundation for housing demand shocks. More importantly, it gives rise to an empirically plausible mechanism that can potentially generate the observed large fluctuations in the priceto-rent ratio and its strong comovement with the house price.

The main insights, however, do not hinge upon the particular way of modeling heterogeneity. We now consider a different type of heterogeneity. Instead of assuming idiosyncratic preference shocks, we consider idiosyncratic income shocks. We show that all the main results obtained above carry over to this alternative setup.

Consider a household family with a continuum of members. All members enjoy the same consumption $c_{t}$. Each member gets a transfer payment $a_{t}$ from the family for purchasing houses in the decentralized housing market. Before their house purchase decisions, they each receives an idiosyncratic shock $\omega_{t}$ so that their effective net worth is $\omega_{t} a_{t}$. Since households with different realizations of $\omega_{t}$ make different house purchasing decisions, the housing services in the utility function for each member are indexed by $\omega_{t}$. The household utility function is given by

$$
\mathbb{E}_{0} \sum_{t=0}^{\infty} \beta^{t}\left[\log c_{t}+\varphi \int_{0}^{\infty} \frac{\left[h_{t}\left(\omega_{t}\right)\right]^{1-\theta}}{1-\theta} d F\left(\omega_{t}\right)\right]
$$

where $h_{t}\left(\omega_{t}\right)$ denotes housing held by the household member with the shock $\omega_{t}$, drawn from the distribution $F(\omega)$. All the other variables and parameters have the same interpretations as in the benchmark model.

The family faces the flow budget constraint

$$
c_{t}+a_{t}=y_{t}+q_{t} \int h_{t-1}\left(\omega_{t-1}\right) d F\left(\omega_{t-1}\right)-\int b_{t-1}\left(\omega_{t-1}\right) d F\left(\omega_{t-1}\right)
$$


where $y_{t}$ denotes endowment (or labor income), $q_{t}$ denotes the house price, and $b_{t-1}\left(\omega_{t-1}\right)$ denotes the last-period borrowing of the member with idiosyncratic income shock $\omega_{t-1}$.

In the decentralized housing markets, the household member with shock $\omega_{t}$ finances house purchases with both internal funds $\omega_{t} a_{t}$ and external debt $b\left(\omega_{t}\right)$, subject to the flow-of-funds constraint

$$
q_{t} h_{t}\left(\omega_{t}\right) \leq \omega_{t} a_{t}+\frac{b_{t}\left(\omega_{t}\right)}{R_{t}}
$$

and the borrowing constraint

$$
\frac{b_{t}\left(\omega_{t}\right)}{R_{t}} \leq \kappa_{t} q_{t} h_{t}\left(\omega_{t}\right)
$$

where $R_{t}$ denotes the risk-free interest rate and $\kappa_{t}$ denotes the loan-to-value ratio, which is common for all borrowers.

Denote by $\lambda_{t}, \eta_{t}\left(\omega_{t}\right)$, and $\pi_{t}\left(\omega_{t}\right)$ the Lagrangian multiplers associated with the constraints (S2), (S3), and (S4), respectively. The first order condition with respect to $c_{t}$ is given by

$$
\frac{1}{c_{t}}=\lambda_{t}
$$

The first order condition with respect to $a_{t}$ implies

$$
\lambda_{t}=\int \eta_{t}\left(\omega_{t}\right) d F\left(\omega_{t}\right)
$$

The first order condition with respect to $h_{t}\left(\omega_{t}\right)$ is given by

$$
\eta_{t}\left(\omega_{t}\right) q_{t}=\varphi\left[h_{t}(\omega)\right]^{-\theta}+\beta \mathbb{E}_{t} \lambda_{t+1} q_{t+1}+\kappa_{t} q_{t} \pi_{t}\left(\omega_{t}\right)
$$

The first order condition with respect to $b_{t}\left(\omega_{t}\right)$ is

$$
\frac{1}{R_{t}} \eta_{t}\left(\omega_{t}\right)=\beta E_{t} \lambda_{t+1}+\frac{1}{R_{t}} \pi_{t}\left(\omega_{t}\right)
$$

These optimizing conditions have similar interpretations as in the benchmark model.

Aggregating the binding flow-of-funds constraints across all members, we obtain

$$
\int_{0}^{\infty} q_{t} h_{t}\left(\omega_{t}\right) d F\left(\omega_{t}\right)=a_{t} \int \omega_{t} d F\left(\omega_{t}\right)+\int \frac{b_{t}\left(\omega_{t}\right)}{R_{t}} d F\left(\omega_{t}\right) .
$$

Imposing the market clearing conditions that $\int h_{t}(\omega) d F(\omega)=1$ and that $\int b_{t}(\omega) d F(\omega)=$ 0 , along with the normalization assumption that $\int \omega_{t} d F\left(\omega_{t}\right)=1$, we have

$$
q_{t}=a_{t}
$$

A household member with a sufficiently high $\omega_{t}$ does not face a binding borrowing constraint, so that $\pi_{t}\left(\omega_{t}\right)=0$. From Eq. (S7) and (S8), we obtain that those 
unconstrained agents have the identical marginal utility of housing and thus identical holdings of housing units. A low-income member will face binding borrowing constraints, leading to an endogenenous cut-off point $\omega_{t}^{*}$ in the support of the distribution of the idiosyncratic income shocks, such that the liquidity constraint (S4) binds if and only if $\omega_{t}<\omega_{t}^{*}$. The following proposition summarizes the allocation of housing across constrained vs. unconstrained members and also the determination of the cutoff point.

Proposition S1. There exist an unique cut-off $\omega_{t}^{*}$ such that the borrowing constraint (S4) binds if and only if $\omega_{t}<\omega_{t}^{*}$. The housing demand for each member is given by

$$
h_{t}\left(\omega_{t}\right)=\left\{\begin{array}{ll}
\frac{\omega_{t}^{*}}{1-\kappa_{t}} & \text { if } \omega_{t} \geq \omega_{t}^{*} \\
\frac{\omega_{t}}{1-\kappa_{t}} & \text { if } \omega_{t}<\omega_{t}^{*}
\end{array}\right\}
$$

The cutoff point $\omega_{t}^{*}$ is determined from the housing market clearing condition, and it is given by

$$
\int_{\omega_{\min }}^{\omega_{t}^{*}} \omega f(\omega) d \omega+\left(1-F\left(\omega_{t}^{*}\right)\right) \omega_{t}^{*}=1-\kappa_{t}
$$

which define an implicit function of $\omega_{t}^{*}=\omega^{*}\left(\kappa_{t}\right)$.

Proof. The proof is analogous to that in the baseline model with idiosyncratic taste shocks.

It is also straightforward to show that the Lagrangian multipliers $\eta_{t}\left(\omega_{t}\right)$ and $\pi_{t}\left(\omega_{t}\right)$ are given by

$$
\begin{gathered}
\eta_{t}\left(\omega_{t}\right)=\left\{\begin{array}{cc}
R_{t} \beta E_{t} \lambda_{t+1} & \text { if } \omega_{t} \geq \omega_{t}^{*} \\
R_{t} \beta E_{t} \lambda_{t+1}+\frac{1}{q_{t}}\left(1-\kappa_{t}\right)^{\theta-1}\left[\left(\omega_{t}\right)^{-\theta}-\left(\omega_{t}^{*}\right)^{-\theta}\right] & \text { if } \omega_{t}^{j}<\omega_{t}^{*}
\end{array}\right\} . \\
\pi_{t}\left(\omega_{t}\right)=\left\{\begin{array}{cc}
0 & \text { if } \omega_{t} \geq \omega_{t}^{*} \\
\frac{1}{q_{t}}\left(1-\kappa_{t}\right)^{\theta-1}\left[\left(\omega_{t}\right)^{-\theta}-\left(\omega_{t}^{*}\right)^{-\theta}\right] & \text { if } \omega_{t}<\omega_{t}^{*}
\end{array}\right\} .
\end{gathered}
$$

It then follows from the Euler equation (S6) and Eq. (S12) that

$$
\lambda_{t}=R_{t} \beta E_{t} \lambda_{t+1}+\frac{\varphi}{q_{t}}\left(1-\kappa_{t}\right)^{\theta-1} \int_{\omega_{\min }}^{\omega_{t}^{*}}\left[\omega^{-\theta}-\omega_{t}^{*-\theta}\right] f(\omega) d \omega .
$$

Aggregating the housing Euler equations across individuals and using the housing allocations in Eq (S10), we obtain the aggregate housing Euler equation

$$
\lambda_{t} q_{t}=\mathbb{E}_{t} \beta \lambda_{t+1} q_{t+1}+\zeta\left(\kappa_{t}\right)
$$


where

$$
\zeta\left(\kappa_{t}\right) \equiv \varphi\left[\frac{\omega_{t}^{*}}{1-\kappa_{t}}\right]^{-\theta}+\varphi\left(1-\kappa_{t}\right)^{\theta-1} \int_{\omega_{\min }}^{\omega_{t}^{*}}\left(\omega^{-\theta}-\omega_{t}^{*-\theta}\right) f(\omega) d \omega .
$$

In the expression for $\zeta\left(\kappa_{t}\right)$, the first term is the average marginal utility across all home buyers and the second term is the liquidity premium, which is positive if and only if $\omega<\omega_{t}^{*}$.

The aggregated housing Euler equation (S15) provides a mapping between our model here with heterogeneous incomes and the representative-agent economy. In particular, if $\zeta\left(\kappa_{t}\right)=\varphi_{t}$, then the equilibrium house price in this heterogeneousagent model coincides with that in the representative agent model. Thus, this model with heterogeneous income also provides a microeconomic foundation for aggregate housing demand shocks. The presence of the liquidity premium here breaks the tight link between the house price and the rent, creating room for large fluctuations in the price-to-rent ratio following credit supply shocks.

Similar to the benchmark heterogeneous-agent economy, changes in credit supply conditions represented by changed in $\kappa_{t}$ can drive changes in aggregate housing demand and thus the house price as well. To see this, note that the house price needs to satisfy the marginal agent's housing Euler equation

$$
q_{t} \frac{\eta_{t}^{*}}{\lambda_{t}}=\mathbb{E}_{t} \beta \frac{\lambda_{t+1}}{\lambda_{t}} q_{t+1}+M R S_{t}^{*}
$$

where $\eta_{t}^{*}=R_{t} \mathbb{E}_{t} \beta \frac{\lambda_{t+1}}{\lambda_{t}}$ increases with the risk-free interest rate $R_{t}$ and the term $M R S_{t}^{*}$ denotes the marginal agent's marginal rate of substitution between housing and nonhousing consumption. For any given interest rate, the house price increases with the marginal agent's MRS, which is given by

$$
M R S_{t}^{*}=\frac{\varphi}{\lambda_{t}}\left(\omega_{t}^{*}\right)^{-\theta}\left(1-\kappa_{t}\right)^{\theta} .
$$

The housing market clearing condition in Eq. (S11) implies that $\omega^{*}$ decreases with $\kappa$. In particular,

$$
\frac{\partial \omega_{t}^{*}}{\partial \kappa_{t}}=-\frac{1}{1-F\left(\omega_{t}^{*}\right)}<0
$$

We can then derive the elasticity of $M R S_{t}^{*}$ with respect to $\kappa_{t}$ given by

$$
e_{M R S^{*}, \kappa} \equiv \frac{\partial M R S_{t}^{*}}{\partial \kappa_{t}} \frac{\kappa_{t}}{M R S_{t}^{*}}=\theta \kappa_{t}\left[\frac{1}{\omega_{t}^{*}\left[1-F\left(\omega_{t}^{*}\right)\right]}-\frac{1}{1-\kappa_{t}}\right]>0
$$

where the last inequality follows from the housing market clearing condition in equation (S11). Thus, an increase in credit supply raises the MRS of the marginal agent. It follows that, for any given interest rate, the house price increase with credit supply. 


\section{Appendix B. A heterogeneous-Agent MODEL With Endogenous LABOR} SUPPLY AND CAPITAL ACCUMULATION

This section shows that the benchmark heterogeneous-agent model that we presented in Section III can be generalized to incorporate endogenous labor supply and capital accumulation. We follow Lagos and Wright (2005) and Wen (2009) by assuming quasi-linear preferences to keep the model tractable (see also Wen (2015) and Dong and Wen (2019)).

The economy is populated by a continuum of households with unit measure indexed by $j$. The household has quasi-linear preferences, with the period utility function

$$
u_{t}^{j}=\log c_{t}^{j}+\varphi \varepsilon_{t}^{j} \frac{\left(h_{t}^{j}\right)^{1-\theta}}{1-\theta}-\psi n_{t}^{j},
$$

where $c_{t}^{j}, h_{t}^{j}$, and $n_{t}^{j}$ denote the household's consumption, housing, and labor supply, respectively; the term $\varepsilon_{t}^{j}$ is an idiosyncratic shock to housing preferences, as in our baseline model; and the parameters $\varphi$ and $\psi$ measure the relative utility weights on housing and leisure, respectively. The linearity of the utility function in labor hours is the key to simplifying aggregation, as we show below.

Households supply labor and capital to firms. They also trade houses and a riskfree bond. Each period is divided into two sub-periods. In the first sub-period, households decide their labor supply, consumption, and investment in capital; and firms make production decision. In the second sub-period, idiosyncratic shocks are realized and households trade houses and bonds. Let $b_{t-1}^{j}, k_{t-1}^{j}, h_{t-1}^{j}$ denote household j's pre-determined stocks of bonds, capital, and housing, respectively. The household faces the flow-of-funds constraint

$$
q_{t}\left(h_{t}^{j}-h_{t-1}^{j}\right) \leq \frac{b_{t}^{j}}{R_{t}}+m_{t}^{j}
$$

where

$$
m_{t}^{j} \equiv w_{t} n_{t}^{j}+r_{t} k_{t-1}^{j}-b_{t-1}^{j}-c_{t}^{j}-\left[k_{t}^{j}-(1-\delta) k_{t-1}^{j}\right]
$$

Here $w_{t}$ and $r_{t}$ are real wage and rental rate of capital, respectively. In the first subperiod, the household $j$ receives labor income and capital rents, which are used to finance consumption spending and capital investment after paying off the debt $b_{t-1}^{j}$. At the end of the first sub-period, the household has a remaining balance of $m_{t}^{j}$. In the second sub-period, the household uses the internal funds $m_{t}^{j}$ and external debt $b_{t}^{j}$ to finance new house purchases at the price $q_{t}$. 
Borrowing is subject to the collateral constraint

$$
\frac{b_{t}^{j}}{R_{t}} \leq \kappa_{t} q_{t} h_{t}^{j}
$$

The household's optimizing decision problem can be separated into a decision for consumption, labor supply, and capital investment in the first sub-period and subsequently, a decision for housing and borrowing in the second sub-period.

Denote by $a_{t}^{j} \equiv m_{t}^{j}+q_{t} h_{t-1}^{j}$ the total wealth of the household. The first sub-period decision problem can be described by the value function

$$
V_{t}\left(k_{t-1}^{j}, b_{t-1}^{j}, h_{t-1}^{j}\right)=\max _{c_{t}^{j}, k_{t}^{j}, n_{t}^{j}} \log c_{t}^{j}-\psi n_{t}^{j}+\int J_{t}\left(k_{t}^{j}, a_{t}^{j}, \varepsilon_{t}^{j}\right) d F\left(\varepsilon_{t}^{j}\right),
$$

subject to the budget constraint

$$
a_{t}^{j}=w_{t} n_{t}^{j}+r_{t} k_{t-1}^{j}+q_{t} h_{t-1}^{j}-b_{t-1}^{j}-c_{t}^{j}-\left[k_{t}^{j}-(1-\delta) k_{t-1}^{j}\right] .
$$

Here $V_{t}\left(k_{t-1}^{j}, b_{t-1}^{j}, h_{t-1}^{j}\right)$ is his value function in the beginning of first sub-period and $J_{t}\left(k_{t}^{j}, a_{t}^{j}, \varepsilon_{t}^{j}\right)$ is the value function in the second sub-period, which is defined as

$$
J_{t}\left(k_{t}^{j}, a_{t}^{j}, \varepsilon_{t}^{j}\right)=\max _{h_{t}^{j}, b_{t}^{j}}\left\{\varphi \varepsilon_{t}^{j} \frac{\left(h_{t}^{j}\right)^{1-\theta}}{1-\theta}+\beta \mathbb{E}_{t} V_{t+1}\left(k_{t}^{j}, b_{t}^{j}, h_{t}^{j}\right)\right\},
$$

subject to the budget constraint in the second sub-period

$$
q_{t} h_{t}^{j} \leq \frac{b_{t}^{j}}{R_{t}}+a_{t}^{j}
$$

and the collateral constraint (S23).

To solve the household's problem, we adopt a conjecture and verification strategy. In particular, based on the quasi-linear preferences, we conjecture that the value function takes the form

$$
V_{t}\left(k_{t-1}^{j}, b_{t-1}^{j}, h_{t-1}^{j}\right)=V_{k t} k_{t-1}^{j}-V_{b t} b_{t-1}^{j}+V_{h t} h_{t-1}^{j}+V_{0 t}
$$

where the coefficients $V_{k t}, V_{b t}, V_{h t}$ and $V_{0 t}$ depends on the aggregate state variables. We also conjecture that the value function $\int J_{t}\left(k_{t}^{j}, a_{t}^{j}, \varepsilon_{t}^{j}\right) d F\left(\varepsilon_{t}^{j}\right)$ is a quasi-linear function of the state variables, and it is given by

$$
\int J_{t}\left(k_{t}^{j}, a_{t}^{j}, \varepsilon_{t}^{j}\right) d F\left(\varepsilon_{t}^{j}\right)=J_{k t} k_{t}^{j}+g_{t}\left(a_{t}^{j}\right)
$$

where $J_{k t}$ depends on the aggregate state variables and $g_{t}\left(a_{t}^{j}\right)$ is a nonlinear function.

With these conjecture, we can rewrite the household problem as $V_{k t} k_{t-1}^{j}-V_{b t} b_{t-1}^{j}+V_{h t} h_{t-1}^{j}+V_{0 t}=\max _{c_{t}^{j}, k_{t}^{j}, n_{t}^{j}} \log c_{t}^{j}-\psi n_{t}^{j}+\beta \mathbb{E}_{t} V_{k t+1} k_{t}^{j}+g_{t}\left(a_{t}^{j}\right)+\beta \mathbb{E}_{t} V_{0 t+1}$ 
and $g_{t}\left(a_{t}^{j}\right)=\int G_{t}\left(a_{t}^{j}, \varepsilon_{t}^{j}\right) d F\left(\varepsilon_{t}^{j}\right)$, with $G_{t}\left(a_{t}^{j}, \varepsilon_{t}^{j}\right)$ given as

$$
G_{t}\left(a_{t}^{j}, \varepsilon_{t}^{j}\right)=\max _{h_{t}^{j}, b_{t}^{j}}\left\{\varphi \varepsilon_{t}^{j} \frac{\left(h_{t}^{j}\right)^{1-\theta}}{1-\theta}+\beta \mathbb{E}_{t} V_{h t+1} h_{t}^{j}-\beta \mathbb{E}_{t} V_{b t+1} b_{t}^{j}\right\} .
$$

Thus, $h_{t}^{j}$, and $b_{t}^{j}$ depend only on $\varepsilon_{t}^{j}$ and $a_{t}^{j}$.

Denote by $\lambda_{t}^{j}, \eta_{t}^{j}$, and $\pi_{t}^{j}$ as the Lagrangian multipliers associated with constraints (S25), (S27), and (S23) respectively. The first order conditions for consumption, labor, capital are

$$
\begin{gathered}
\frac{1}{c_{t}^{j}}=\lambda_{t}^{j}, \\
w_{t} \lambda_{t}^{j}=\psi,
\end{gathered}
$$

and

$$
\lambda_{t}^{j}=\beta \mathbb{E}_{t} V_{k t+1}
$$

respectively. Equations (S30) and (S31) imply that consumption is equal across all households. The first-order condition with respect to $a_{t}^{j}$ yields

$$
g_{t}^{\prime}\left(a_{t}^{j}\right)=\lambda_{t}^{j}=\frac{\psi}{w_{t}} \equiv \lambda_{t}
$$

which implies that $a_{t}^{j}$ is identical across households. Thus, independent of the realized idiosyncratic shocks, all households enter the second sub-period with identical holdings of total wealth, because they can adjust labor supply to completely insure against the idiosyncratic risks. This is only true if the marginal utility of increasing labor is constant.

Applying the envelop theory, we have

$$
\begin{aligned}
V_{k t} & =\lambda_{t}\left(1+r_{t}-\delta\right)=\frac{\psi}{w_{t}}\left(1+r_{t}-\delta\right), \\
V_{b t} & =\lambda_{t}=\frac{\psi}{w_{t}} \\
V_{h t} & =\lambda_{t} q_{t}=\frac{\psi}{w_{t}} q_{t} .
\end{aligned}
$$

So indeed $V_{k t}, V_{b t}$ and $V_{h t}$ depends only on aggregate variables, verifying our initial conjecture. In addition, $V_{0 t}$ can be written as

$$
V_{0 t}=\max _{c_{t}^{j}}\left\{\log c_{t}^{j}-\psi \frac{c_{t}^{j}}{w_{t}}+\beta \mathbb{E}_{t} V_{0 t+1}\right\}=\log w_{t}-\log \psi-1+\beta \mathbb{E}_{t} V_{0 t+1}
$$

Thus, $V_{0 t}$ also depends on aggregate variables only. 
The optimizing investment decision (S32) then implies that

$$
\lambda_{t}=\beta E_{t} \lambda_{t+1}\left(1+r_{t}-\delta\right)
$$

We summarize these results in the following Lemma.

Lemma S1. All households will have the same level of consumption and same level of wealth in the second sub-period. In particular, $a_{t}^{j}=a_{t}$ for all $j$.

The first order condition with respect to $h_{t}^{j}$, and $b_{t}^{j}$ yields

$$
\eta_{t}^{j} q_{t}=\frac{\varphi \varepsilon_{t}^{j}}{\left(h_{t}^{j}\right)^{\theta}}+\underbrace{\beta \mathbb{E}_{t} \lambda_{t+1} q_{t+1}}_{\beta \mathbb{E}_{t} V_{h t+1}}+\kappa_{t} q_{t} \pi_{t}^{j}
$$

and

$$
\eta_{t}^{j}=R_{t} \underbrace{\beta \mathbb{E}_{t} \lambda_{t+1}}_{\beta \mathbb{E}_{t} V_{b t+1}}+\pi_{t}^{j}
$$

To see that the function $g_{t}\left(a_{t}^{j}\right)$ indeed has some curvature, we need to compute $h_{t}^{j}, \eta_{t}^{j}$ and $\pi_{t}^{j}$ as functions $a_{t}^{j}$ and $\varepsilon_{t}^{j}$. The above two equations yields

$$
\eta_{t}^{j}=\frac{1}{\left(1-\kappa_{t}\right) q_{t}}\left[\frac{\varphi \varepsilon_{t}^{j}}{\left(h_{t}^{j}\right)^{\theta}}+\beta E_{t} \lambda_{t+1} q_{t+1}-\kappa_{t} q_{t} \beta R_{t} E_{t} \lambda_{t+1}\right]
$$

and

$$
\pi_{t}^{j}=\frac{1}{\left(1-\kappa_{t}\right) q_{t}}\left[\frac{\varphi \varepsilon_{t}^{j}}{\left(h_{t}^{j}\right)^{\theta}}+\beta E_{t} \lambda_{t+1} q_{t+1}-\kappa_{t} q_{t} \beta R_{t} E_{t} \lambda_{t+1}\right]-R_{t} \beta \mathbb{E}_{t} \lambda_{t+1}
$$

Let us denote $h_{t}^{j}=h_{t}\left(a_{t}^{j}, \varepsilon_{t}^{j}\right), \eta_{t}^{j}=\eta_{t}\left(a_{t}^{j}, \varepsilon_{t}^{j}\right)$, and $\pi_{t}^{j}=\pi_{t}\left(a_{t}^{j}, \varepsilon_{t}^{j}\right)$. Define $\bar{\varepsilon}_{t}^{j} \equiv \bar{\varepsilon}\left(a_{t}^{j}\right)$ such as

$$
\frac{1}{\left(1-\kappa_{t}\right) q_{t}}\left\{\frac{\varphi \bar{\varepsilon}_{t}^{j}}{\left[\frac{a_{t}^{j}}{q_{t}\left(1-\kappa_{t}\right)}\right]^{\theta}}+\beta E_{t} \lambda_{t+1} q_{t+1}-\kappa_{t} q_{t} \beta R_{t} E_{t} \lambda_{t+1}\right\}=R_{t} \beta \mathbb{E}_{t} \lambda_{t+1}
$$

Notice that $\bar{\varepsilon}_{t}^{j}$ increases with $a_{t}^{j}$, or we have $\bar{\varepsilon}^{\prime}\left(a_{t}^{j}\right)>0$. Notice $\pi_{t}^{j}$ is increases in $\varepsilon_{t}^{j}$ and $h_{t}^{j} \leq \frac{a_{t}^{j}}{q_{t}\left(1-\kappa_{t}\right)}$, so $\pi_{t}^{j}>0$ if $\varepsilon_{t}^{j} \geq \bar{\varepsilon}\left(a_{t}^{j}\right)$. Likewise, $\pi_{t}^{j}=0$ if $\varepsilon_{t}^{j}<\bar{\varepsilon}\left(a_{t}^{j}\right)$. Suppose for $\varepsilon_{t}^{j}<\bar{\varepsilon}\left(a_{t}^{j}\right), \pi_{t}^{j}>0$, then $h_{t}^{j}=\frac{a_{t}^{j}}{q_{t}\left(1-\kappa_{t}\right)}$. But since $\pi_{t}^{j}$ is increasing in $\varepsilon_{t}^{j}$, so we must $\pi_{t}^{j}<0$ if $\varepsilon_{t}^{j}<\bar{\varepsilon}\left(a_{t}^{j}\right)$. We hence reach an contradiction. Notice that equation (S40)

$$
\eta_{t}\left(a_{t}^{j}, \varepsilon_{t}^{j}\right)-\eta_{t}\left(a_{t}^{j}, \bar{\varepsilon}_{t}^{j}\right)=\frac{\varphi}{\left(1-\kappa_{t}\right) q_{t}} \max \left\{0, \varepsilon_{t}^{j}-\bar{\varepsilon}_{t}^{j}\right\}
$$


and equation (S39) implies that $\eta_{t}\left(a_{t}^{j}, \bar{\varepsilon}_{t}^{j}\right)=R_{t} \beta \mathbb{E}_{t} \lambda_{t+1}$. So we have

$$
\begin{aligned}
g_{t}^{\prime}\left(a_{t}^{j}\right) & =\int \frac{\partial G_{t}\left(a_{t}^{j}, \varepsilon_{t}^{j}\right)}{\partial a_{t}^{j}} d F\left(\varepsilon_{t}^{j}\right)=\int \eta_{t}\left(a_{t}^{j}, \varepsilon_{t}^{j}\right) d F\left(\varepsilon_{t}^{j}\right) \\
& =R_{t} \beta \mathbb{E}_{t} \lambda_{t+1}+\frac{\varphi}{\left(1-\kappa_{t}\right) q_{t}} \int_{\bar{\varepsilon}_{t}^{j}}^{\varepsilon_{\max }}\left[\varepsilon_{t}^{j}-\bar{\varepsilon}_{t}^{j}\right] d F\left(\varepsilon_{t}^{j}\right),
\end{aligned}
$$

Notice that $\bar{\varepsilon}_{t}^{j}$ is an strictly increasing function of $a_{t}^{j}$, so the last term is a decreasing function of $a_{t}^{j}$. Namely $g_{t}^{\prime \prime}\left(a_{t}^{j}\right)<0$, or $g_{t}\left(a_{t}^{j}\right)$ is a concave function. Then equaiton (S33) can indeed implies that $a_{t}^{j}=a_{t}$. Then we have $\bar{\varepsilon}_{t}^{j}=\bar{\varepsilon}_{t}\left(a_{t}\right) \equiv \varepsilon_{t}^{*}$. Drop the superscript $j$, we hence obtain the same equations as equations (19) and (20). Finally by noticing that in equilibrium $\int b_{t}^{j} d j=0$, and $\int h_{t}^{j} d j=1$, then we obtain $a_{t}=q_{t}$ by equation (S27) as in Section III. In particular, we have

$$
q_{t} \lambda_{t}=\mathbb{E}_{t} \beta \lambda_{t+1} q_{t+1}+\xi\left(\kappa_{t}\right)
$$

where the term $\xi_{t} \equiv \xi\left(\kappa_{t}\right)$ is given by

$$
\xi\left(\kappa_{t}\right) \equiv \varphi\left(1-\kappa_{t}\right)^{\theta} \mathbb{E} \max \left\{\varepsilon, \varepsilon_{t}^{*}\right\}+\kappa_{t} \frac{1}{1-\kappa_{t}} \int_{\varepsilon_{t}^{*}}^{\varepsilon_{\max }}\left(1-\kappa_{t}\right)^{\theta} \varphi\left(\varepsilon_{t}-\varepsilon_{t}^{*}\right) d F\left(\varepsilon_{t}\right),
$$

which is the same housing demand shifter as in the baseline model. To close the model, we assume a competitive firm that produces final output according to $Y_{t}=A X_{t}^{\alpha} N_{t}^{1-\alpha}$, where $X_{t}$ is its capital input and $N_{t}$ is the labor input. The problem for the firm is

$$
\max A X_{t}^{\alpha} N_{t}^{1-\alpha}-r_{t} X_{t}-w_{t} N_{t}
$$

so we have $r_{t}=\alpha \frac{Y_{t}}{X_{t}}$, and $w_{t}=(1-\alpha) \frac{Y_{t}}{N_{t}}$. In equilibrium $X_{t}=\int k_{t-1}^{j} d j \equiv K_{t-1}$, and $N_{t}=\int n_{t}^{j} d j$. Define $C_{t}=\int c_{t}^{j} d j$, we must have

$$
\frac{1}{C_{t}}=\lambda_{t}
$$

And equation (S31) can be written as

$$
\frac{1}{C_{t}}(1-\alpha) \frac{Y_{t}}{N_{t}}=\psi
$$

Equation (S37) then becomes

$$
\frac{1}{C_{t}}=\beta \mathbb{E}_{t} \frac{1}{C_{t+1}}\left[\alpha \frac{Y_{t+1}}{K_{t}}+1-\delta\right]
$$

Finally, aggregating Eq (S25) across all households yields

$$
C_{t}+K_{t}-(1-\delta) K_{t}=A K_{t}^{\alpha} N_{t}^{1-\alpha}
$$

where we have used the conditions $w_{t} \int n_{t}^{j} d j+r_{t} \int k_{t-1}^{j} d j=w_{t} N_{t}+r_{t} K_{t-1}=Y_{t}$, $q_{t} \int h_{t-1}^{j} d j=a_{t}=\int a_{t}^{j} d j$, and $\int b_{t-1}^{j} d j=0$. 
With the Lagrangian multiplier $\lambda_{t}$ substituted out using Eq. (S44), the equilibrium paths of the endogenous variables $\left\{q_{t}, C_{t}, N_{t}, K_{t}\right\}_{t=0}^{\infty}$ are completely characterized by Equations (S42), (S45)-(S47).

To see the mapping between the heterogeneous-agent model and the representativeagent model, consider the representative household's utility-maximizing problem

$$
\max _{\left\{C_{t}, H_{t}, K_{t+1}, N_{t}\right\}} \mathbb{E}_{0} \sum_{t=0}^{\infty} \beta^{t}\left[\log C_{t}+\xi_{t} \frac{H_{t}^{1-\theta}}{1-\theta}-\psi N_{t}\right]
$$

subject to

$$
C_{t}+q_{t}\left(H_{t}-H_{t-1}\right)+K_{t}-(1-\delta) K_{t-1} \leq A K_{t}^{\alpha} N_{t}^{1-\alpha}
$$

It is easy to see that the equilibrium paths for $\left\{q_{t}, C_{t}, N_{t}, K_{t+1}\right\}_{t=0}^{\infty}$ in this representativeagent economy are governed by the same equations (S42), and (S45)-(S47). If the reduced-form housing demand shock $\xi_{t}$ in this representative-agent model equals to the housing demand shifter $\xi\left(\kappa_{t}\right)$ in the heterogeneous-agent model (see Eq. (S43)), then we obtain an observational equivalence between the two models.

\section{Appendix C. Proof to Proposition 2}

Proof. Eq. (24) implies that

$$
\varphi \varepsilon\left(h_{t}(\varepsilon)\right)^{-\theta}= \begin{cases}\varphi \varepsilon\left(1-\kappa_{t}\right)^{\theta}, & \text { if } \varepsilon \geq \varepsilon_{t}^{*}, \\ \varphi \varepsilon_{t}^{*}\left(1-\kappa_{t}\right)^{\theta}, & \text { if } \varepsilon<\varepsilon_{t}^{*}\end{cases}
$$

Integrating over $\varepsilon$ yields the average marginal utility in (31).

To obtain the liquidity premium, we combine (19) and (20) to obtain

$$
\pi_{t}(\varepsilon)=\frac{1}{1-\kappa_{t}}\left[\frac{\varphi \varepsilon\left[h_{t}(\varepsilon)\right]^{-\theta}+\beta \mathbb{E}_{t} \lambda_{t+1} q_{t+1}}{q_{t}}-\beta R_{t} \mathbb{E}_{t} \lambda_{t+1}\right]
$$

It follows that

$$
\pi_{t}(\varepsilon)-\pi_{t}\left(\varepsilon_{t}^{*}\right)=\frac{1}{1-\kappa_{t}} \frac{\varphi \varepsilon\left[h_{t}(\varepsilon)\right]^{-\theta}-\varphi \varepsilon_{t}^{*}\left[h_{t}\left(\varepsilon_{t}^{*}\right)\right]^{-\theta}}{q_{t}} .
$$

Since $\pi_{t}\left(\varepsilon_{t}^{*}\right)=0$, we obtain

$$
\pi_{t}(\varepsilon)=\frac{\varphi}{\left(1-\kappa_{t}\right) q_{t}} \max \left\{0,\left(\varepsilon-\varepsilon_{t}^{*}\right)\left(1-\kappa_{t}\right)^{\theta}\right\}
$$

where we have substituted out $h_{t}(\varepsilon)$ using (24). Multiplying (S51) by $\kappa_{t} q_{t}$ and integrating over $\varepsilon \in\left[\varepsilon_{t}^{*}, \bar{\varepsilon}\right]$, we obtain the expression for the liquidity premium in (31). 


\section{APPENDIX D. RENTAL MARKETS}

We now introduce an explicit rental market for housing into our model. We show that, in this environment with a frictionless rental market, the market rental rate for housing corresponds to the average MRS across all agents, as does the implicit rent in the benchmark model (see Eq. (37)). The incorporation of a frictionless rental market represents a minimal departure from our benchmark model.

Consider a model economy in which the household enjoys utility from consumption of non-housing goods $c_{t}$ and housing services. Housing services are derived from either rental units or owner-occupied units. The household family can perfectly insure risks in goods consumption and rental services, so that those markets are frictionless. However, owner-occupied housing markets have frictions; and in particular, members with different taste shocks trade owner-occupied housing units in a decentralized market subject to collateral constraints. We implement this model structure by adopting a particular timing of decisions. In the beginning of each period $t$, the household family chooses goods consumption $c_{t}$ and rental services $\ell_{t}$, as well as some internal funds $a_{t}$ to be allocated to individual members in the decentralized owner-occupied housing market. After these decisions, an idiosyncratic taste shock $\varepsilon$ drawn from the distribution $F(\varepsilon)$ is realized, and household members go out to the decentralized housing market to purchase additional housing units. Such purchases can be financed by either internal funds or external debt (or both). The borrowing capacity of an individual member with taste shock $\varepsilon$ is limited by a fraction $\kappa_{t}$ of the value of the housing unit $h(\varepsilon)$.

The household has the expected utility function

$$
\mathbb{E}_{0} \sum_{t=0}^{\infty} \beta^{t}\left[\log c_{t}+\varphi \int_{0}^{\infty} \frac{\varepsilon_{t}\left[\ell_{t}+h_{t}\left(\varepsilon_{t}\right)\right]^{1-\theta}}{1-\theta} d F\left(\varepsilon_{t}\right)\right]
$$

where $\ell_{t}$ denotes the rental housing services, and the other notations are identical to those in the benchmark model. The decisions for both goods consumption and rental services consumption are made in the beginning of the period, before the realization of the idiosyncratic shock $\varepsilon_{t}$. Once the idiosyncratic shock is realized, the household is split into a continuum of members, each indexed with the realized taste shock $\varepsilon_{t}$, and they all go out to a decentralized housing market to purchase owner-occupied units $h\left(\varepsilon_{t}\right)$. We assume that the household is endowed with a fixed amount of rental housing units $\ell$. The household faces the budget constraint

$$
c_{t}+a_{t}+r_{h t} \ell_{t}=y_{t}+q_{t} \int h_{t-1}\left(\varepsilon_{t-1}\right) d F\left(\varepsilon_{t-1}\right)-\int b_{t-1}\left(\varepsilon_{t-1}\right) d F\left(\varepsilon_{t-1}\right)+r_{h t} \ell .
$$


In the decentralized housing markets, a member with idiosyncratic shock $\varepsilon_{t}$ finances his spending on new housing $q_{t} h_{t}\left(\varepsilon_{t}\right)$ using both internal funds $a_{t}$ received from the household family and external borrowing $b_{t}\left(\varepsilon_{t}\right)$ at the interest rate $R_{t}$. The flow-offunds constraint for the member indexed by $\varepsilon_{t}$ is given by

$$
q_{t} h_{t}\left(\varepsilon_{t}\right) \leq a_{t}+\frac{b_{t}\left(\varepsilon_{t}\right)}{R_{t}}
$$

The borrowing capacity of the member with $\varepsilon_{t}$ is subject to the collateral constraint

$$
\frac{b_{t}\left(\varepsilon_{t}\right)}{R_{t}} \leq \kappa_{t} q_{t} h_{t}\left(\varepsilon_{t}\right)
$$

where the loan-to-value ratio $\kappa_{t} \in[0,1]$ represent exogenous shocks to credit conditions. We further impose the short-sale restriction on owner-occupied units, such that

$$
h_{t}\left(\varepsilon_{t}\right) \geq 0, \forall \varepsilon_{t} \sim F(\varepsilon) .
$$

Denote by $\lambda_{t}, \eta_{t}\left(\varepsilon_{t}\right), \pi_{t}\left(\varepsilon_{t}\right)$ and $\mu_{t}\left(\varepsilon_{t}\right)$ the Lagrangian multipliers associated with Equations (S53)-(S56), respectively. Then the first order condition with respect to $c_{t}$ is given by

$$
\frac{1}{c_{t}}=\lambda_{t}
$$

The first order condition with respect to $a_{t}$ implies

$$
\lambda_{t}=\int \eta_{t}\left(\varepsilon_{t}\right) d F\left(\varepsilon_{t}\right)
$$

A marginal unit of goods transferred to individual members for housing purchases reduces family consumption by one unit and hence the utility cost is $\lambda_{t}$. The utility gain from this transfer is the shadow value of newly purchased housing (i.e., $\eta_{t}\left(\varepsilon_{t}\right)$ ) averaged across all members.

The first order condition with respect to $\ell_{t}$ implies

$$
r_{h t}=\frac{1}{\lambda_{t}} \varphi \int \varepsilon_{t}\left[\ell_{t}+h_{t}\left(\varepsilon_{t}\right)\right]^{-\theta} d F\left(\varepsilon_{t}\right)
$$

Thus, the market rental price equals the average MRS between housing and nonhousing consumption across all members of the household.

The first order condition with respect to $h_{t}\left(\varepsilon_{t}\right)$ yields

$$
\eta_{t}\left(\varepsilon_{t}\right) q_{t}=\varphi \varepsilon_{t}\left[\ell_{t}+h_{t}\left(\varepsilon_{t}\right)\right]^{-\theta}+\beta \mathbb{E}_{t} \lambda_{t+1} q_{t+1}+\kappa_{t} q_{t} \pi_{t}\left(\varepsilon_{t}\right)+\mu_{t}\left(\varepsilon_{t}\right)
$$

The first-order condition with respect to $b_{t}\left(\varepsilon_{t}\right)$ is given by

$$
\eta_{t}\left(\varepsilon_{t}\right)=\beta R_{t} \mathbb{E}_{t} \lambda_{t+1}+\pi_{t}\left(\varepsilon_{t}\right) .
$$


The solution to this problems can be characterized by two cutoffs. Intuitively, a member with a sufficiently high marginal utility of housing (i.e., high $\varepsilon_{t}$ ) wants to purchase as much owner-occupied housing units as allowed by the borrowing constraint, whereas a member with a sufficiently low marginal utility would not want to buy new owner-occupied units at all. The solution to the owner-occupied housing is formally described by the following proposition.

Proposition 1. There exists a cutoff point $\varepsilon_{t}^{*}$ in the support of the distribution $F(\varepsilon)$, such that

$$
h_{t}\left(\varepsilon_{t}\right)=\left\{\begin{array}{cc}
\frac{1}{1-\kappa_{t}} & \text { if } \varepsilon_{t} \geq \varepsilon_{t}^{*}, \\
\max \left\{\left(\frac{\varepsilon_{t}}{\varepsilon_{t}^{*}}\right)^{\frac{1}{\theta}}\left(\ell_{t}+\frac{1}{1-\kappa_{t}}\right)-\ell_{t}, 0\right\} & \text { otherwise, }
\end{array}\right.
$$

In equilibrium $\ell_{t}=\ell$. Define $\varepsilon_{\ell t}^{*}$ as

$$
\varepsilon_{\ell t}^{*}=\left(\frac{\ell_{t}}{\ell_{t}+\frac{1}{1-\kappa_{t}}}\right)^{\theta} \varepsilon_{t}^{*}
$$

The cutoff point $\varepsilon_{t}^{*}$ is determined by

$$
\int_{\varepsilon_{\ell t}^{*}}^{\varepsilon_{t}^{*}}\left[\left(\frac{\varepsilon_{t}}{\varepsilon_{t}^{*}}\right)^{\frac{1}{\theta}}\left(\ell_{t}+\frac{1}{1-\kappa_{t}}\right)-\ell_{t}\right] f(\varepsilon) d \varepsilon+\int_{\varepsilon_{t}^{*}}^{\varepsilon_{\max }} \frac{1}{1-\kappa_{t}} f(\varepsilon) d \varepsilon=1
$$

Proof. For a household member with $\varepsilon_{t} \geq \varepsilon_{t}^{*}$, the borrowing constraint is binding and hence the flow of funds constraint yields

$$
h_{t}\left(\varepsilon_{t}\right)=\frac{a_{t}}{q_{t}\left(1-\kappa_{t}\right)}=\frac{1}{1-\kappa_{t}},
$$

which is independent of $\varepsilon_{t}$.

If $\varepsilon_{t}<\varepsilon_{t}^{*}$, then $\pi_{t}\left(\varepsilon_{t}\right)=0$. We have

$$
\eta_{t}\left(\varepsilon_{t}\right)=\beta R_{t} E_{t} \lambda_{t+1}=\eta_{t}\left(\varepsilon_{t}^{*}\right) \equiv \eta_{t}^{*}
$$

Furthermore, with $\pi_{t}\left(\varepsilon_{t}\right)=0$, Eq. (19) implies that

$$
\eta_{t}^{*} q_{t}=\varphi \varepsilon_{t}\left[\ell_{t}+h_{t}\left(\varepsilon_{t}\right)\right]^{-\theta}+\beta E_{t} \lambda_{t+1} q_{t+1}+\mu_{t}\left(\varepsilon_{t}\right),
$$

if $\mu_{t}\left(\varepsilon_{t}\right)=0$, then we must have

$$
\varphi \varepsilon_{t}\left[\ell_{t}+h_{t}\left(\varepsilon_{t}\right)\right]^{-\theta}=\varphi \varepsilon_{t}^{*}\left[\ell_{t}+h_{t}\left(\varepsilon_{t}^{*}\right)\right]^{-\theta}=\varphi \varepsilon_{t}^{*}\left(\ell_{t}+\frac{1}{1-\kappa_{t}}\right)^{-\theta} .
$$

Simple algebra yields that $h_{t}\left(\varepsilon_{t}\right)=\left(\frac{\varepsilon_{t}}{\varepsilon_{t}^{*}}\right)^{\frac{1}{\theta}}\left(\ell_{t}+\frac{1}{1-\kappa_{t}}\right)-\ell_{t}$. By the definition of $\varepsilon_{\ell t}^{*}$ we have $h_{t}\left(\varepsilon_{t}\right) \geq 0$ if $\varepsilon_{t} \geq \varepsilon_{\ell t}^{*}$. Finally, if $\varepsilon_{t}<\varepsilon_{\ell t}^{*}, h_{t}\left(\varepsilon_{t}\right)=0$. The housing market clearing 
condition then implies

$$
\int_{\varepsilon_{\ell t}^{*}}^{\varepsilon_{t}^{*}}\left[\left(\frac{\varepsilon_{t}}{\varepsilon_{t}^{*}}\right)^{\frac{1}{\theta}}\left(\ell_{t}+\frac{1}{1-\kappa_{t}}\right)-\ell_{t}\right] f(\varepsilon) d \varepsilon+\int_{\varepsilon_{t}^{*}}^{\bar{\varepsilon}} \frac{1}{1-\kappa_{t}} f(\varepsilon) d \varepsilon=1 .
$$

We now consider how aggregate housing demand and thus the house price are determined in equilibrium. For simplicity, we focus on the special case with $\theta=0$. The following proposition summarizes the main result.

Proposition 2. In the special case with $\theta=0$, the aggregate housing Euler equation is given by

$$
q_{t} \lambda_{t}=\beta \mathbb{E}_{t} \lambda_{t+1} q_{t+1}+\xi_{t}
$$

where the term $\xi_{t}$ is given by

$$
\xi_{t}=\varphi\left[1+\frac{\kappa_{t}}{1-\kappa_{t}} \int_{\varepsilon_{t}^{*}}^{\bar{\varepsilon}}\left(\varepsilon_{t}-\varepsilon_{t}^{*}\right) f(\varepsilon) d \varepsilon+\int_{0}^{\varepsilon_{t}^{*}}\left(\varepsilon_{t}^{*}-\varepsilon_{t}\right) f(\varepsilon) d \varepsilon\right]
$$

which is increasing in credit availability $\kappa_{t}$. The market rent is given by

$$
r_{h t}=\frac{\varphi}{\lambda_{t}}
$$

which is independent of $\kappa_{t}$.

Proof. The proof is analogous to that in the baseline heterogeneous-agent model with no explicit rental market.

It follows that the equilibrium house price in this heterogeneous-agent model with a rental market is identical to that in the benchmark model, and both coincides with the house price in the representative-agent economy if $\xi_{t}=\varphi_{t}$. Furthermore, since the house price increases with credit availability $\kappa_{t}$, whereas the market rent is independent of $\kappa_{t}$, the price-to-rent ratio increases with $\kappa_{t}$.

Thus, in this model with an explicit rental market, we obtain qualitatively similar results as those in the benchmark model.

\section{Appendix E. DATA AND REGRESSIONS}

In the empirical analysis in Section VI, we use both cross-country data and U.S. regional data. 
E.1. International data. The cross-country data are an unbalanced panel of 25 advanced economies, covering the years from 1965 to 2013. The time series in each country includes the household debt-to-GDP ratio, the mortgage spread, the house price, and the rent. The household debt-to-GDP ratio and the mortgage spread are the same as those used by Mian et al. (2017). The house price and the rent series are taken from the OECD Main Economic Indicators through Haver Analytics. We deflate the nominal rent series using the consumer price index in each country (or the Harmonized Index of Consumer Prices for the European countries in our sample).

Table S1 presents the list of the countries and some summary statistics of the data.

E.2. U.S. regional data. The U.S. regional data are an unbalanced panel, consisting of 21 MSAs, covering the years from 1978 to 2017. The time series in each MSA includes the housing loan-to-price ratio and the effective mortgage interest rate, both taken from the Federal Housing Finance Board (FHFB). The effective mortgage rate is defined as the contract mortgage rate plus fees and charges amortized over a 10-year period, the estimated average life of conventional mortgages. The mortgage spread used in our regression is the spread between the effective mortgage rates and the 10year Treasury yields. The data include the house price index in each MSA from the Federal Housing Finance Agency (FHFA), the rent index, which is measured by the "rent of primary residence" in the expenditure categories of the consumer price index (CPI-All Urban Consumers) for each MSA. We convert the nominal house price and the nominal rent into real units by using the MSA-level CPI.

Table S2 presents the list of the MSAs and some summary statistics of the data. 
TABLE S1. Summary of countries in the sample and key statistics

\begin{tabular}{|c|c|c|c|c|c|c|c|c|c|}
\hline Country & Start Year & Mean $\Delta D^{H H}$ & $\mathrm{SD} \Delta D^{H H}$ & Mean $I^{M S}$ & $\mathrm{SD} I^{M S}$ & Mean $\Delta \ln (P)$ & $\mathrm{SD} \Delta \ln (P)$ & Mean $\Delta \ln (R)$ & $\mathrm{SD} \Delta \ln (R)$ \\
\hline Australia & 1979 & 2.22 & 2.58 & 1.14 & 1.65 & 3.19 & 6.60 & 0.56 & 2.03 \\
\hline Austria & 1997 & 0.69 & 1.30 & 0.98 & 0.54 & 1.62 & 2.82 & 1.09 & 2.05 \\
\hline Belgium & 1982 & 0.86 & 1.13 & 0.94 & 0.71 & 2.40 & 4.15 & 0.46 & 1.38 \\
\hline Canada & 1971 & 1.44 & 2.40 & 2.10 & 0.72 & 2.51 & 6.28 & -1.23 & 2.17 \\
\hline Czech Republic & 2003 & 2.06 & 1.21 & 1.40 & 0.61 & -2.88 & 2.71 & 2.98 & 4.85 \\
\hline Denmark & 1996 & 3.65 & 4.06 & 0.31 & 0.52 & 2.87 & 7.90 & 0.58 & 0.77 \\
\hline Finland & 1981 & 1.22 & 2.47 & -0.33 & 1.28 & 2.19 & 9.40 & 0.09 & 3.57 \\
\hline France & 1979 & 1.10 & 1.22 & 0.36 & 0.85 & 2.04 & 5.44 & 0.82 & 1.37 \\
\hline Germany & 1972 & 0.50 & 1.82 & 0.98 & 0.69 & -0.30 & 2.39 & 0.39 & 1.67 \\
\hline Greece & 2000 & 4.00 & 2.18 & 1.23 & 0.36 & 0.06 & 8.67 & -0.40 & 2.79 \\
\hline Hungary & 2000 & 2.14 & 3.21 & 3.76 & 2.56 & -7.07 & 5.03 & 1.46 & 3.32 \\
\hline Ireland & 2004 & 5.01 & 8.46 & 0.54 & 0.73 & -4.10 & 11.50 & 3.08 & 18.87 \\
\hline Italy & 1996 & 1.59 & 1.16 & 1.52 & 1.06 & 0.57 & 5.20 & 0.62 & 1.67 \\
\hline Japan & 1981 & 0.57 & 1.94 & 0.64 & 0.80 & -0.19 & 4.02 & 0.46 & 1.20 \\
\hline Korea, Rep. & 2001 & 2.86 & 3.28 & -0.04 & 0.19 & 2.06 & 4.87 & -0.38 & 1.69 \\
\hline Mexico & 2005 & 0.51 & 0.65 & 7.26 & 0.78 & 0.01 & 2.07 & -1.44 & 0.83 \\
\hline Netherlands & 1992 & 3.76 & 2.73 & 1.24 & 0.72 & 3.16 & 6.17 & 1.17 & 1.65 \\
\hline Norway & 1988 & 0.56 & 3.44 & 1.14 & 1.16 & 2.88 & 7.93 & 0.87 & 1.38 \\
\hline Poland & 2003 & 2.18 & 2.46 & 0.96 & 0.87 & -5.20 & 1.86 & 0.77 & 1.52 \\
\hline Portugal & 1991 & 3.50 & 2.49 & 1.56 & 2.09 & -1.22 & 4.03 & 1.05 & 3.08 \\
\hline Spain & 1982 & 1.80 & 2.69 & 1.01 & 1.37 & 3.01 & 9.87 & 0.63 & 2.13 \\
\hline Sweden & 1987 & 1.19 & 2.83 & 0.32 & 0.58 & 3.35 & 7.20 & 1.93 & 3.90 \\
\hline Switzerland & 2001 & 1.25 & 3.22 & 0.98 & 0.58 & 2.91 & 2.88 & 0.87 & 0.88 \\
\hline U.K. & 1974 & 1.55 & 2.52 & 0.70 & 0.67 & 2.24 & 9.31 & 1.61 & 3.13 \\
\hline U.S. & 1965 & 0.69 & 2.21 & 1.74 & 0.54 & 1.22 & 4.19 & 0.66 & 1.48 \\
\hline
\end{tabular}

Notes: This table lists the 25 countries and the years covered used in the international data sample. The variable $\Delta D^{H H}$ denotes the year-over-year changes in the household debt-to-GDP ratio, $I^{M S}$ denotes the mortgage spread dummy, which equals one if the mortgage spread is below the median and zero otherwise (the mortgage spread is the difference between the mortgage interest rate and the 10-year sovereign bond yields), $\Delta \ln (P)$ denotes the year-over-year log-changes in the real house price, and $\Delta \ln (R)$ denotes the year-over-year log-changes in the real rent. 
TABLE S2. Summary of countries in the sample and key statistics

\begin{tabular}{|c|c|c|c|c|c|c|c|c|c|}
\hline MSA & Start Year & Mean $\Delta D^{H H}$ & $\mathrm{SD} \Delta D^{H H}$ & Mean $I^{M S}$ & $\mathrm{SD} I^{M S}$ & Mean $\Delta \ln (P)$ & $\mathrm{SD} \Delta \ln (P)$ & Mean $\Delta \ln (R)$ & $\mathrm{SD} \Delta \ln (R)$ \\
\hline ATL & 1979 & 0.13 & 2.65 & 1.69 & 0.99 & 0.46 & 4.27 & 0.35 & 2.43 \\
\hline $\mathrm{BON}$ & 1979 & 0.20 & 4.39 & 1.81 & 1.03 & 2.40 & 7.43 & 0.75 & 2.44 \\
\hline ВTM & 1979 & 0.10 & 2.39 & 1.69 & 0.95 & 1.04 & 5.78 & 1.36 & 1.86 \\
\hline $\mathrm{CHG}$ & 1979 & 0.49 & 3.68 & 1.71 & 0.98 & 0.59 & 5.49 & 0.81 & 1.73 \\
\hline DAA & 1979 & 0.25 & 3.12 & 1.73 & 0.95 & -0.01 & 7.81 & 0.09 & 2.10 \\
\hline DFW & 1979 & -0.04 & 3.48 & 1.72 & 0.99 & -0.01 & 4.12 & 0.21 & 2.68 \\
\hline DNV & 1979 & 0.02 & 2.86 & 1.60 & 1.04 & 1.33 & 4.54 & 0.51 & 2.37 \\
\hline $\mathrm{HON}$ & 1979 & 0.01 & 3.99 & 1.35 & 1.04 & 2.44 & 20.53 & 0.52 & 1.76 \\
\hline HTN & 1979 & -0.09 & 2.55 & 1.74 & 1.03 & 0.22 & 4.43 & 0.36 & 3.17 \\
\hline LNA & 1979 & 0.00 & 2.87 & 1.53 & 1.06 & 1.84 & 9.50 & 0.97 & 2.19 \\
\hline MIM & 1979 & 0.12 & 2.95 & 1.76 & 1.04 & 1.21 & 9.52 & 0.46 & 2.18 \\
\hline MSP & 1979 & 0.36 & 3.06 & 1.60 & 1.00 & 0.53 & 5.08 & 0.25 & 2.16 \\
\hline NYT & 1979 & 0.38 & 2.54 & 1.72 & 1.11 & 1.88 & 7.27 & 0.88 & 1.44 \\
\hline PHI & 1979 & 0.26 & 2.36 & 1.79 & 1.02 & 1.59 & 5.45 & 0.53 & 2.04 \\
\hline $\mathrm{PHO}$ & 2002 & -0.04 & 2.40 & 2.01 & 0.68 & 1.69 & 14.77 & 0.60 & 2.86 \\
\hline SDI & 1979 & -0.26 & 3.54 & 1.40 & 1.13 & 1.19 & 8.80 & 0.65 & 3.01 \\
\hline SFC & 1979 & 0.01 & 3.76 & 1.44 & 1.07 & 2.81 & 8.18 & 1.23 & 2.83 \\
\hline STL & 1979 & 0.18 & 3.69 & 1.72 & 0.99 & 0.23 & 3.84 & 0.09 & 1.76 \\
\hline STW & 1979 & 0.00 & 2.81 & 1.60 & 1.01 & 1.95 & 6.48 & 0.60 & 2.34 \\
\hline TMA & 1997 & -0.06 & 2.49 & 2.06 & 0.64 & 2.01 & 10.50 & 0.72 & 1.87 \\
\hline WSH & 1979 & 0.10 & 2.39 & 1.69 & 0.95 & 1.43 & 6.86 & 1.30 & 1.39 \\
\hline
\end{tabular}

Notes: This table lists the 21 MSAs and the years covered in the U.S. regional data sample. The variable $\Delta D^{H H}$ denotes the year-over-year changes in the housing loan-to-price ratio, $I^{M S}$ denotes the mortgage spread dummy, which is one if the mortgage spread is below median (the mortgage spread is the difference between the effective mortgage interest rate and the 10-year Treasury yields), $\Delta \ln (P)$ denotes the year-over-year log-changes in the real house price, and $\Delta \ln (R)$ denotes the year-over-year log-changes in the real rent.

Federal Reserve Bank of San Francisco, Hong Kong University of Science and Technology, Federal Reserve Bank of Atlanta, Emory University, and NBer 